\title{
SOBRE LAS FUENTES PÚBLICAS EN LOS PUEBLOS MORISCO-ANDALUSÍES EN TUNICIA, EN LOS SIGLOS XVII, XVIII Y XIX*
}

\author{
Abdel-Hakim Gafsi-Slama \\ Historiador, Arqueólogo, \\ Instituto Nacional del Patrimonio, Ministerio de Cultura, Túnez
}

La presente nota se centra esencialmente en la alimentación en agua de las zonas de implantación morisco-andalusí, en Tunicia ${ }^{1}$, a la luz de crónicas, relatos de viaje, documentos de archivos y arqueológicos, investigaciones, etc.

Para el estudio de este aspecto, tenemos que indicar al mismo tiempo el origen de esa agua (fuentes, pozos, lluvia) y seguir los trabajos de aprovechamiento hidráulico realizados: erección de fuentes-abrevaderos, acondicionamiento de fuentes, cisternas, pozos, y restauración del antiguo acueducto romano y su desviación, recordando así la política del agua seguida por los distintos soberanos, partiendo desde la llegada en masa al actual territorio tunecino de los moriscos-andalusíes, hacia 1609.

A la luz de las crónicas, esta política se caracteriza por una voluntad de asegurarse el aprovisionamiento de agua: compra de $\operatorname{pozos}^{2} \mathrm{y}$ de animales destinados a hacer funcionar las norias ${ }^{3}$, constitución de fundaciones religiosas (hubs, waqf) para su mantenimiento, erección de fuentes ${ }^{4} \mathrm{y}$ concesión de ayudas ${ }^{5}$.

* $\quad$ Artículo publicado en francés. Ver África (Túnez) XV (1997) 233-266.

$1 \quad$ Ver mapa n. ${ }^{\circ} 1$.

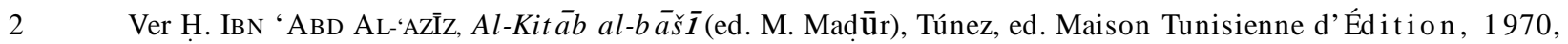
p. 313.

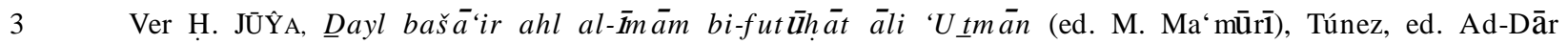
al-‘Arabiyya li-l-Kitāb, 1975, p. 158.

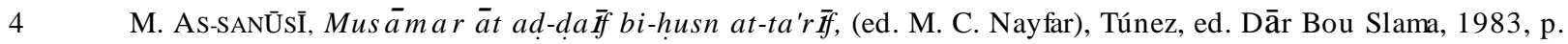
33 .

5 Concesión de dos reales (riyāl, piastra) al que ha anunciado que se ha llenado la fasqiyya (“ cisterna” o forma de balsa) de la laguna salada y barrio de El Mellassine (ver Archivo Nacional Tunecino -A.N.T.-, registro 277, p. 63, año 1795). Ofrecimiento de alimentos gratuitos el primer día de la construcción de una cisterna (A.N.T., registro 1771, p. 182, año 1773). 
Esta política buscaba, evidentemente, la bendición de $\operatorname{Dios}^{6}$ y también el agradecimiento de

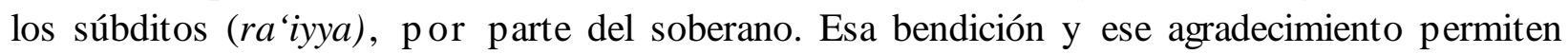
asegurar, por una parte, el presente y el porvenir de la sociedad, y, por otra parte, refuerzan el papel predominante del poder político en esa sociedad. Esta política está destinada, por tanto, a mantener un orden y a reforzar un poder político, muchas veces usurpado. Eso explica el carácter a la vez utilitario y religioso de las diferentes obras emprendidas.

Entre los argumentos invocados por los cronistas para justificar esa política del agua figuran la falta de lluvia7, el interés por el 'umrān (“civilización”)", la prosperidad económica ${ }^{9}$, la acumulación de riquezas ${ }^{10}$ y el aumento de la población ${ }^{11}$. En definitiva, esa política intenta asegurar la seguridad y la paz en el país ${ }^{12}$.

\section{ESA AGUA, ¿ERA SUFICIENTE?}

En 1298, el valenciano Al-‘Abdarī lamentaba la falta de agua potable en Túnez ${ }^{13}$. El agua era suficiente según Ibn Abī Dīnār, cronista tunecino del siglo XVII ${ }^{14}$. Estas afirmaciones contradictorias justifican una nueva evaluación, que vamos a intentar, centrando nuestro examen en el estudio de las fuentes públicas y otras fuentes de aprovisionamiento de agua ${ }^{15}$.

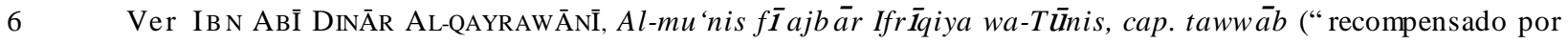
las buenas obras”), p. 207.

7 Ver IBN ‘ABD AL-‘AZĪz, o.c., p. 313.

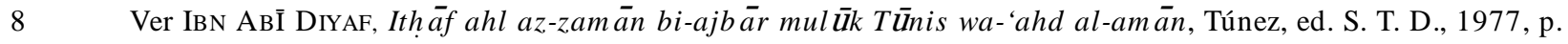
77.

9 Ver H. Jū̂̀̂, o. c., p. 158.

10 La fuente pública de Yúsuf Dey en Bizerta servía para los pescadores de coral (ver A.N.T., legajo 388, cartón 32, documento 19, año 1872, y nuestro artículo «Lamha hawla sabīl Yūsuf Dāy bi-madīna Binzart» [Visión de conjunto sobre la fuente de YúsufDey en la ciudad de Bizerta], Arab Historical Review for Ottoman Studies, Zaghouan, 9-10, 1994, 317-322).

Ver IBN ‘ABD AL-'AZĪZ, o. c., p. 310.

La constante preocupación de los soberanos por traer agua al interior de las murallas, para asegurar el avituallamiento de las guarniciones en caso de asedio, es muy frecuente, según G. MARÇAIs, Manuel d'art musulman, t. I, París, ed. Picard, 1926, p. 138.

Ver A. Daoulatli, Tunis sous les Hafsides, Túnez, ed. Institut National d’Archéologie, 1976, p. 153; R. BrunschVIG, La Berbérie Orientale sous les Hafsides, t. I, París, ed. Maisonneuve, 1947, p. 352.

Ver o. c., t. II, p. 211.

Desgraciadamente, no hemos podido consultar el libro de Izzet Kambaracilar, Istanbul sebilleri [Las fuentes de Estambul], Estambul, 1938, p. 72, citado por R. MANTRAN, Istanbul dans la seconde moitié du XVIIe siècle, París, 1962, ed. Maisonneuve, p. 680. 
La primera observación que se puede sacar de este estudio es que las fuentes públicas (sabî, sabbala, massāsa) llevan a menudo, a diferencia de las otras obras hidráulicas (cisternas, estanques, pozos, acueductos...) inscrip ciones que alaban a los fundadores de esas obras y recuerdan a los usuarios la piedad de esos fundadores.

Con ese mismo espíritu tanto los cronistas como los poetas hacen elogios de esas construcciones ${ }^{16}$, dando así una impresión de grandeza y de "genialidad" para esos bienhechores. Hast a aparecen títulos de "propaganda” política y religiosa: “Alī Bāša II era "El Fundador de Mádrasas (“colegios") ${ }^{17}$ y Fuentes ${ }^{18 ”}$.

Objeto de descrip ciones de cronistas, a veces minuciosas, y tema de interés, inspiración y admiración de los viajeros ${ }^{19} \mathrm{y}$ de los pintores europeos ${ }^{20}$, las fuentes públicas ocupan un lugar importante en la vida de la ciudad.

\section{TERMINOLOGÍA.}

Las ap elaciones relativas a las fuentes públicas pueden dar lugar a confusiones. En efecto, tanto en los documentos archivísticos como en las crónicas o en los trabajos de investigación (de arqueología, de historia, de geografía...), muchas veces no se hace distinción entre sab11, siqaya, sabbala, y massasa $a^{21}$.

Originariamente, el "sabīl” -pronunciado en árabe local "sbil”- se refiere a una ruta, vía o camino, pero la palabra se ap lica también a las fuentes públicas ${ }^{22}$.

En efecto, el "sabīl" en Tunicia puede designar a la "sabbāla" (fuente provista de chupadero) $)^{23}$. En Marruecos, el sabīl es el abrevadero público alimentado por una noria ${ }^{24}$. A Hama

Ver Roy - P OINSSOT, Inscriptions arabes de Kairouan, t. II, fasc. I, París, ed. Klincksieck, 1950, p. 85.

Ver nuestro artículo, A. El GAFSI, «La Médersa des Morisques-Andalous à Tunis», Sharq Al-Ándalus. Estudios Árabes, Alicante, 5, 1988, 169-180.

Ver A.N.T., registro 2306, año 1782.

Ver P. SeBAG, «La négociation de Laurent d’ Arvieux (12 juin 1666 - 15 août 1666)», IBLA, Túnez, 147, 1981, p. 2; nuestro artículo, A. GAFsI, «Zaghouan à l' époque islamique», en Zaghouan et sa région, Zaghouan, ed. Municipalité de Zaghouan, 1990, p. 7; J. Despois, La Tunisie orientale, Sahel et Basse Steppe, Paris, ed. Presse Universitaire de France, 1955, p. 226.

La misma confusión se encuentra en las superficies de agua, māŷyil,jazna, fisqiyya.

Ver Encyclopédie de l’Islam, vol. 4, p. 25, art. «sabīl». al-‘Atīka, 1966, p. 116. 
(Siria), es el depósito de agua o la balsa ${ }^{25}$. En Estambul, puede designar la fuente monumental, por op osición a la çeçme, fuente de barrio ${ }^{26}$.

De todas formas, las p alabras "sabīl", "siqāy a" o "sabbāla” son, en Tunicia, fuentes públicas construidas con piedras o mampostería, provistas de chupadero y acompañadas de un abrevadero. La fuente sirve para los humanos mientras que el abrevadero está destinado a los animales. Así pues, en Tunicia, sabīl, siqāya, sabbāla y massāāsa designan generalmente fuentes-abrevaderos.

Dicho esto, conviene ahora abordar el examen del aspecto exterior de esas fuentes-abrevaderos.

\section{ARQUITECTURA DE LAS FUENTES-ABREVADEROS.}

Vamos a limitarnos, en la may oría de los casos, a las fuentes públicas que aún se conservan y vamos a describirlas tal y como están en la actualidad. La más sencilla se presenta en forma de alcachofa o cebolla de cobre (massāsa), de plomo o de otro material, que emerge de la pared a la altura de un hombre. El sobrante de agua se derrama en una balsa pegada a un muro decorado con baldosas de loza (el Sabīl as-Sūq, en Zaghouan).

Entre las que llevan una inscripción, podemos citar los sabiles de Bizerta (Najjarine, Sidi Gaagaa $^{27}$, Bab al-Madina ${ }^{28}$, Bab al-Khoukha ${ }^{29}$. La inscrip ción de cada una de ellas, generalmente en árabe, a veces en turco, se encuentra sobre una placa de mármol o de piedra calcárea (kaddal) pegada a una pared.

Las fuentes con arco se distinguen por la riqueza de su decoración. En efecto, la cara del pilón, así como el arco que se alza detrás, están tapizados con baldosas de loza o de azulejos $(z a l l \hat{y} \hat{y})^{30}$, como el Sabīl ar-Rahba, en Zaghouan. El "sbil” de Bab al-Khukha de Bizerta está decorado con semi-columnas emp otradas que llevan un arco de colores alternos. Las dos columnas del "sbil" as-Sūq, en el pueblo de Solimán, están sostenidas por dos pilastras de piedra talladas (jar $\hat{y})$ que soportan un arco de descarga, adornado en el centro con un lazo. Al fondo de este arco

25 Ver K. ChAHAde, «Les bassins et fontaines à Hama», Annales archéologiques arabes syriennes, Damasco, 28-29, 1977, p. 231.

Ver R. MANTRAN, o. c.

La pared en la que está inserta la inscripción está decorada con un reborde de tejas huecas.

La placa tiene encima un frontón rectangular. La escritura es de estilo cúfico.

Ver tabla n. ${ }^{\circ} 1$.

Sabīl Bab al-Khukha, en Bizerta, y Sabbāla al-Bhaiem, en Ghar al-Malh, están desprovistas de baldosas, pero están decoradas con un reborde, con tejas huecas o modillones en forma de dientes de sierra. Esas baldosas de loza son generalmente del estilo llamado de Qallālīn (“Ceramistas”, nombre de barrio de andalusíes en el suburbio norte de Túnez, o nombre de un pueblo al sureste de Tunicia), que se caracteriza por una decoración de cipreses estilizados o de minaretes alargado, de color azul. 
se encuentra un nicho muy hermoso, encuadrado con baldosas de azulejos y con una reja de hierro que rep osa sobre una placa de mármol que se apoya en tres consolas. Esta reja sirve para proteger el agua de la balsa.

Pero el "sbil” de Yúsuf Dey, en Bizerta, sigue siendo el monumento más hermoso de este tipo. Construido por un inmigrante morisco-andalusí, se caracteriza por su precioso aparejo de piezas de mármol, alternando los negros y los blancos, con superposición de un reborde de tejas redondeadas de color verde. El arco está ligeramente sobresaliente, con una inscripción rectangular delimitada por dos columnas de mármol con capiteles de estilo hafsí. El intradós está decorado con una bellísima inscripción, en árabe y en turco.

El "sbil” llamado de Sāhib at-Tab‘a es monumental, pero con una decoración muy sobria. Está protegido por una construcción rectangular abovedada. El parapeto que cubre las bóvedas espinadas está provisto de modillones en forma de dientes de sierra y descansa sobre cuatro arcos. Un reborde de tejas redondas corre por encima de esos arcos. La fuente propiamente dicha está compuesta por cinco nichos ciegos en piedra tallada (jar $\hat{y}$ ) adornados cada uno de ellos con tres lazos. Cada nicho tenía originariamente un chupadero (massāsa) actualmente desaparecido. La balsa que rodeaba a esos nichos sirve de abrevadero ${ }^{31}$. Este "sbil" se parece a muchas fuentes de mezquitas, puestas en el interior de nichos decorados con mosaicos o azulejos (zallîy). A veces esos nichos están remplazados por conchas salientes que echan el agua direct amente en la balsa de abluciones ${ }^{32}$.

Para completar esta visión general, conviene presentar rápidamente otros tipos de fuentes que no tienen equivalentes en los pueblos andalusíes.

Así, la fuente-abrevadero de Bab Sidi Abdesselème, en Túnez, la única que se ha salvado de una política "modernizante", se present a exteriormente bajo la forma de una cúpula bulbosa recubierta con pequeñas tejas verdes planas imbricadas mutuamente. Esta especie de gorra recubre una cúpula semiesférica que encierra dos sarcófagos romanos que sirven de abrevaderos. Esta cúpula descansa sobre una loggia cuadrada sostenida por pilares y por dos arcos de herradura ${ }^{33}$.

Algunos documentos de archivo nos indican, por otra parte, que la sabbāla de Bāb Sa‘ādūn,que no existe ya actualmente, comportaba un pórtico (bortal) y un frontón (ŷabha) con arcos de diversos colores alternos ${ }^{34}$.

31 Hay que recordar a este propósito que la fuente de Bab Aliwa, en Túnez, descrita por G. MARÇAIS, o. c., II, p. 888, tenía casi la misma estructura.

32 Ver nuestro artículo, A. GAFSI, «El agua en las mezquitas de los pueblos andalusíes», en Agua y poblamiento musulmán, Benissa (Alicante), ed. Ajuntament, 1988, 55-58.

Ver S. M. ZBiss, La Médina de Tunis, Túnez, S. N. A. A., 1981, p. 26. Est a clas e de sabīl se encuentra en la zona residencial de Túnez de La Manouba (Sabīl Șāhị at -Tab“a). El “sbil” de Al-Kubba al-Hamrà, del palacio de El Bardo, mencionado por IBN ABĪ DĪYĀF, o. c., t. III, 1963, p. 47, ¿ tenía la misma estructura? 
Entre las fuentes privadas descritas por los viajeros europeos podemos citar la del pueblo morisco-andalusí de Djedeida: «las habitaciones son como las demás, con oro y azul, con trabajos de estuco y fuentes por todas partes, en un conjunto pavimentado con mármol» ${ }^{35}$.

Ximénez, el religioso trinitario español que visitó el pueblo morisco-andalusí de Grombalia en 1727, menciona fuentes en el palacio de Mustafá Cardanash (el morisco Mustafá de Cárdenas) en los términos siguientes: «la casa tiene dos jardines y muy buenas fuentes, con un estanque de agua» ${ }^{36}$. Refiriéndose al mismo palacio, su contemp oráneo el viajero francés Peyssonnel menciona varias fuentes: «il y a de beaux jardins avec un grand bassin, quantité de fontaines» ${ }^{37}$.

Esta clase de fuentes en los palacios podrían parecerse a las del Morkad, cerca de la Kasbah (alcazaba) que domina Túnez, descrita por Dolot en 1908: «Au centre de cette cour, entièrement dallée s'élève une jolie fontaine en marbre blanc, formée de trois vasques sup erposées et recouvertes d'une sorte de kiosque présentant sur chaque face une triple arcature mauresque, dont les douze colonnes ajoutées aux quatre autres qui s'élèvent dans l'intérieur supp ortent quatre petites coup oles et cinq voûtes d'arête d'une extrême légèreté; les murs extérieurs sont couronnés de tuiles creuses vernissées, dont la couleur verte s'harmonise avec le feuillage des mûriers plantés aux quatre coins"38.

De todas formas, las fuentes públicas, en los pueblos o en Túnez, se distinguen por su arquitectura proporcionada y por su sobria elegancia. «Cette architecture qui n'a pas atteint la somptuosité et la parure raffinée des fontaines du Maroc, mais surp asse celle d'Alger», escribe Georges Marçais ${ }^{39}$. A pesar de todo, las fuentes siguen siendo pequeñas maravillas de la arquitectura tradicional tunecina y rincones de luz, de aire y de frescor en el tejido urbano tradicional.

Un punto de vista merece comentario especial: el sistema hidráulico empleado en las fuentes. Como hemos ya evocado, ese sistema se apoya en el principio de los vasos comunicantes. En efecto, el agua se sacaba por aspiración o succión, por medio de un tubo de cobre a la altura de la boca y saliendo del muro, unido a la balsa de aprovisionamiento que estaba más alejada y cuya altura era superior a la del

Ver P. SeBAG, “L'escale..., p. 67. Laurent d’Arvieux señala una fuente en el Dīwān, sede de la milicia en Túnez, según P. SEBAG, «La négociation...”, p. 87. ¿Se trata de la fuente “fawwāra” mencionada por IBN “ABD AL-'AZĪZ, o. c., p. 328?

En S. M. Zbiss - A. H. Gafsi - M. Boughanmi - M. de Epalza, Études sur les Morisques Andalous, Túnez, 1983, p. 86, traducción francesa del texto editado por M. de EpAlZA, « Nuevos documentos sobre descendientes de moriscos en Túnez en el siglo XVIII», en Studia historica et philologica in honor em M. Batllori, Roma, 1984, p. 223. Ximénez indica que el pueblo andalusí de Testur está desprovisto de fuentes, en los textos traducidos y editados, en ambos trabajos arriba mencionados, pp. 82 y 219, respectivamente.

O. .., p. 173.

Ver G. Dolot, « Note sur la caserne Saussier», Revue Tunisienne, Túnez, 1908, p. 296. 
tubo $^{40}$.

Hay que advertir que ese sistema se empleaba ya en las fuentes de la Musallà al-‘'̄dayn (“Oratorio de las Dos Fiestas”), en Túnez, desde fines del siglo XIV ${ }^{41}$. Ese sistema es menos elaborado, por tanto, que el del “sbil” de Bir Baruta, en Kairuán, dotado, según Saladin, de un verdadero grifo ${ }^{42}$.

\section{LOCALIZACIÓN DEL AGUA (ver tablas n. ${ }^{\circ} 1$ y 2).}

De estas tablas, evidentemente aproximativas, se deduce que las fuentes públicas ("sabīl”, “siqāya”, "sabbāla”, "massāsa”) existen en varios pueblos moriscos-andalusíes (Bizerta, Ghar El Melh, Zaghouan, Grish El Wad, Djedeida, Grombalia...). Esta localización indica también una distribución muy desigual: ocho en Bizerta, cinco en Zaghouan, uno en Grich El Wad). ¿Se trata de resultados de factores económicos o de factores naturales?

La respuesta es evidentemente difícil, porque nos faltan a menudo descripciones precisas, y las informaciones que han llegado hasta nosotros son raras, imprecisas y tardías.

Partiendo de algunas indicaciones disp onibles ${ }^{43}$, sobre la población tunecina en el siglo XIX, podemos suponer que el número de las fuentes es prop orcional al efectivo demográfico (500 hombres en Bizerta y sólo 100 en Grish El Wad). En cambio, Túnez, cuya población se calcula llegaría a los 80.000 personas, tiene unas 50 fuentes públicas ${ }^{44}$.

Desgraciadamente, no tenemos más indicaciones para proceder a otras comparaciones.

La existencia, por otra parte, de una actividad económica intensa, representada por el número de los zocos (zoco de los armeros, de los herreros, de los carpinteros, en Bizerta), podría servir de indicio para explicar el número de fuentes.

En efecto, el examen de la localización de las fuentes públicas nos permite constatar que las fuentes están cerca de los centros económicos (zocos). Es el caso de los “sbil” de Najjarine (“Carpinteros”) y de Sidi Gaagaa en Bizerta, y sobre todo en Túnez (8 sbiles).

Esas tablas hacen ap arecer igualmente que esas fuentes están repartidas en diversos puntos

40 Los tubos del “sbil” de La Kasbah eran obra de artesanos griegos y judíos, según texto de A.N.T., registro 2308, p. 63.

41 Ver ZARKAŠĪ, o. c., p. 116.

42 H. Saladin, «Un robinet de marbre trouvé en Tunisie», Bulletin Archéologique du Comité des Travaux Historiques et Scientifiques, París, 1913, 285-289.

Ver nuestro artículo, A. GAFSI, «Esquisse de l'urbanisme des villages ruraux andalous du XVIIe siècle», en $L a$ Ci u dad Islámica, Zaragoza, 1991, 135-158, y L. VALENSI, Fellahs tunisiens. L'économie rurale et la vie des campagnes aux 18e et 19e siècles, París, Mouton, 1977, p. 17.

Ver L. VAlEnsi, o. c. Fez tenía 80 fuentes (según A. BEL, Zahrat al-as, Argel, Carbonel, 1923, p. 81) y Ceuta 25 (según E. LÉVI-PROVEnÇAL, «Une description de Ceuta musulmane au XVe siècle», Hespéris, Rabat, XII, fasc. 2, 1931, p. 161). 
de la ciudad. Unas están cerca de las puertas, las más numerosas (5 en Bizerta y 10 en Túnez). Otras, en cambio, se encuentran en plazas públicas ( $r a h b a$ ) o en los puntos de encuentro de varias arterias de circulación (8 en Túnez, 1 en Bizerta, 1 en Zaghouan). Eso confirma las observaciones hechas por el viajero alemán Hebeinstreit en el siglo XVIII: «Places publiques qui sont enrichies de jets d'eau et de bassins en marbre» ${ }^{45}$.

Hay que señalar además que algunas fuentes están relacionadas con mezquitas (Solimán y Túnez, por ejemplo). Eso no quiere decir que la fuente esté pegada a la mezquita, porque puede estar también separada o alejada (el sbil de Solimán, por ejemplo).

Se deduce también, de esta presentación de las fuentes públicas en esos pueblos, que no están pegadas a las medersas o madrasa-s (“colegios”), como en Túnez antes de 1609 y en Egipto en la Edad Media ${ }^{46}$. Esta observación de Marçais sólo puede aplicarse a la fuente de la Mádrasa Al-Bachía en Túnez, que está adjunta a este colegio ${ }^{47}$.

Las observaciones hechas sobre el terreno indican también que las fuentes se encuentran en p osición saliente sobre la calle ("sbil” de Bab Al-Madina, en Bizerta, y de Sidi Alí Azouz, en Zaghouan) o en cruces o aberturas de calles (el "sbil” As-Sūq, en Zaghouan). Las fuentes ocupan, pues, una posición importante, privilegiada, en el tejido urbano.

Por su situación, las fuentes contribuyen al decoro y ornato de las calles y plazas. Se trata, por tanto, de un “rincón de atracción”, de “placer”, de “distracción” espacial, pero también un elemento "cultural".

Todas estas observaciones que acabamos de examinar p rueban que las fuentes públicas pertenecen al espacio público (zocos, puertas, plazas, mezquitas...): «la densité des sbils n’est pas sans rapp ort avec l'activité des quartiers concernés : ils sont plus nombreux dans les zones où sont situés les grands souks, les princip ales mosquées» ${ }^{48}$. No se tratapues de la misma concep ción urbana adoptada p or los romanos en Tunicia, donde «casas y monumentos están reagrupados alrededor de la fuente» ${ }^{49}$.

Por consiguiente, la zona residencial de la ciudad parece pobre en fuentes y algunos sectores hasta parecen desprovistos de este elemento urbano (el caso de Túnez es muy significativo). Esta desproporción se nota también a niveles de la Medina (zona residencial) y de los dos suburbios, del norte (Bab Souika) y del sur (Bab Al-Jazira). El primero parece más rico. ¿Fue quizás la

Ver M. FENDRI, «Trois voyageurs allemands en Tunisie au XVIIIe siècle», Revue d’Histoire Maghrébine, Túnez, 35-36, 1984, p. 101.

Ver G. MARÇAIS, o. c., II, p. 888; R. BRUnSCHVIG, o. c., p. 415.

Ver C.-A. Julien, Histoire de l’Afrique du Nord, París, P ayot, 1978, p. 300.

A. RAYmond, «Les fontaines publiques (sabil) du Caire à l’époque ottomane (1517-1798)», Annales Islamologiques, París - El Cairo, XV, 1979, p. 239. de Aix-en-Provence, 1980-1981, p. 87. 
cons ecuencia de la llegada de los moriscos establecidos en este suburbio hacia $1609^{50}$, o es una prolongación de la situación anterior ${ }^{51}$ ?

Las observaciones que vamos a exponer sobre la alimentación de las fuentes podrían quizás proporcionar algunos elementos de respuesta a esta pregunta.

\section{ALIMENTACIÓN DE LAS FUENTES.}

Las instalaciones hidráulicas efectuadas hacia fines del siglo XIV y a lo largo del siglo XV se sitúan esencialmente en Túnez ${ }^{52}$. Por consiguiente, las zonas de las futuras implantaciones morisco-andalusíes no se beneficiaron de esas obras.

\section{A. LAS FUENTES.}

Tanto las crónicas como los documentos de archivos mencionan que a partir del siglo XVII Túnez se alimentaba de las fuentes de Ain Gasaa, de Ain Al-Mettaoui (en el Djebel Al-Ahmar) ${ }^{53}$, de Ain Al-Jellaz ${ }^{54}$ y sobre todo de Zaghouan.

En efecto, Yúsuf Dey (1610-1637) emprendió trabajos hidráulicos de desviación del famoso acueducto romano que venía de Zaghouan, con más de diez kilómetros para llegar a la Kasbah (alcazaba de Túnez) y a su M ezquita May or ${ }^{55}$. El cronista tunecino Ibn Abī Dīnār, muerto en 1681, afirma que este acueducto llega hasta el zoco At-Trouk y a ciertas callejuelas sin salida de la Medina $^{56}$.

La alimentación en agua de Zaghouan se hacía por conductos según el sistema de la “mušāraka”, sistema destinado a distribuir las aguas de las fuentes equitativamente para todos los

50 Ver M. de Epalza - R. PetrT, Études sur les moriscos andalous en Tunisie, Madrid, Instituto Hispano-Árabe de Cultura, 1973, p. 26.

$51 \quad$ Ver A. DaoulatLi, o. c., p. 157.

52 Ver R. BrunschVig, o. c., I, p. 353; A. Daoulatli, o. c., p. 153.

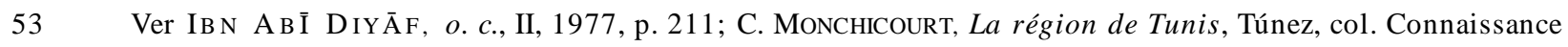
du Maghreb, IX, p. 23; MAs‘'̄DĪ, o. c., p. 93.

Ver A.N.T., registro 1773, p. 211, año 1860.

Ver P. SABAG, «La négociation..., p. 271, nota 88; R. BRUNSCHVIG, o. c., I, p. 352.

Ver IBn AbĪ DinĀR, o. c., p. 240; G. MarÇAIS, o. c., II, p. 887. Hay que advertir a este propósito que el califa hafsí Al-Mustanșir restauró el acueducto el año 1267 y preparó dos aducciones, hacia Túnez y hacia el pueblo de La Ariana, al norte de la capital (ver. A. Daoulatu, o. c., p. 156). El cronista tunecino Ibn 'A bd al-' Azīz mencion a una acequia (sāqiya) que va desde el Djebel Al-Ahmar hacia Túnez (o. c., pp. 85 y 342). Le sigue también Monchicourt, quien advierte que las fuentes de Ain Mettelaoui, en el Djebel Al-Ahmar, fueron conducidas hacia Túnez por un acueducto (o.c., p. 23, nota 2). 
usuarios, según sus necesidades ${ }^{57}$.

Notemos también que los pueblos moriscos-andalusíes disp onen de varias fuentes: Ain Blad y Ain At-Thibban, en Raf Raf; Ain Blad, en Metline. Pero hay que advertir también que estos dos pueblos no disponen de fuentes públicas. Los mismos documentos de archivos señalan, por otra parte, la existencia de conducciones (sāqiya, acequia) y tubos (halāqim) para alimentar la fuente de Yúsuf Dey, de Bizerta. La ciudad y los fuertes de Ghar El Melh estaban alimentados también por una fuente, según esos mismos documentos ${ }^{58}$.

El pueblo de Tébourba, en cambio, disponía de un acueducto desde la ép oca romana ${ }^{59}$. Pero no tenemos ninguna indicación sobre su reempleo o su reutilización por los moriscos andalusíes.

4.B. PozOS.

Algunos documentos de archivos nos informan que varias fuentes de Túnez estaban alimentadas con agua, partiendo de pozos equipados con norias (ver tabla n. ${ }^{\circ} 3$ ). En general, cada fuente estaba alimentada por su propio $\mathrm{pozo}^{60}$.

Otros documentos nos indican que la balsa (la “fesquía”, fasqiyya) de El Mallassine, se llenaba de agua que salía de pozos equipados con norias, y que alimentaba no solamente las dos fuentes de ese barrio, sino también las de Rahbat Al-Ghanam, Al-Morkad y Al-Kaadine ${ }^{61}$.

Desgraciadamente, no disponemos de indicaciones de esta naturaleza sobre las fuentes de los pueblos moriscos-andalusíes. En efecto, un informe realizado en 1888 cuenta 50 pozos con norias en los jardines de Testour ${ }^{62}$, aunque este pueblo no tenía ninguna fuente, según las informaciones sacadas del viaje de Francisco Ximénez, realizado en $1724^{63}$.

En lo que se refiere a los demás pueblos, la pregunta queda sin respuesta, tanto más cuanto

57 Ver S. TAKTAK, Revalorisation du tissu urbain de Zaghouan, Tunis, Institut Tunisien d’Archéologie et d’Urbanisme, 1983, p. 14. Ver también el esquema.

Ver A.N.T., dossier 386, cartón 32, documento 26, año 1870. La sabbāla de Ibn Ammar, en la carretera de Bizerta (ver S. M. ZBiss, Monuments musulmans d'époque hussaynite, Túnez, p. 20), así como la "sabbāla” de Ain Bitar, a la entrada de esa misma ciudad, estaban alimentadas por fuentes. Las fortificaciones de Túnez estaban alimentadas por pozos con noria (ver A.N.T., registro 1773, p. 119, año 1860).

Ver J. P oncet, «La mise en valeur de la Basse Vallée de la Medjerda», Annales de Géographie, París, 347, 1956, p. 205, nota 1.

Ver S. M. ZBIss, Monuments musulman s..., p. 20, y A.N.T., dossier 700/4, cartón 62, año 1800, y año 1876; registre 2307, p. 1, año 1800; MAsudi, o. c., p. 131; IBN ‘ABD AL-'AZİZ, o. c., p. 313. de Al-Mallassine. ¿ Se trata de una simple conducción de agua? LÉVI-PROVENÇAL, o. c., p. 161.

Ver nota 35. 
que los pozos mandados perforar por los diferentes beys husainíes en la carretera que unía Túnez con la ciudad de Béjà ${ }^{64}$ (zona de implantación morisco-andalusí por antonomasia), no pueden informarnos sobre las modalidades de alimentación en agua y sobre la utilización de norias en esa región. Estos pozos “oficiales” no se utilizaban para el regadío o la alimentación de los pueblos, sino que servían para aprovisionar en agua potable la Mahalla o mhalla (ejército encargado de recoger los impuestos) $)^{65}$.

Los pozos que alimentaban las fuentes públicas en Túnez o en esos pueblos morisco-andalusíes tienen generalmente una pared circular. La pared está revestida de un muro de ladrillos llenos o de modillones. Dos murillos de ladrillo lleno o de piedra tallada (“juwanah”, ýǟ̄ih) soportan la noria y sirven para hacer subir el precioso líquido de la capa freática ${ }^{66}$.

Para concluir, hay que señalar que no disponemos de indicaciones precisas sobre la prospección, el sondeo, la construcción de los $\operatorname{pozos}^{67}$ y el personal especializado encargado de los sondeos. Sólo figura el pocero “Bay ar” en la documentación de la que disponemos ${ }^{68}$.

\section{C. AlimENTACIÓN POR CISTERNAS}

Hemos encontrado en la obra de Ibn Abī Dīnār ${ }^{69}$ que las “siqaya” (plural árabe de säqiya, acequia) de Bab Sidi Abdesselem y de Bab Al-Fallah, en Túnez, estaban alimentadas en agua a partir de los depósitos rellenados por las aguas de lluvia. El cronista no menciona ni pozos, ni noria.

64 Ver S. M. ZBiss, Monuments musulmans..., p. 20.

65 La mahalla podía también aprovisionarse en agua de pozos del palacio del Bardo (ver S. M. ZBISS, id., p. 20) o de Ras At-Tabia y Radès (ver IBN ‘ABD Al-'AZĪz, o. c., p. 310).

Ver A. SaAdaoui, o. c., p. 326. Al parecer, el pozo con gradas no ha existido en Tunicia (ver Encyclopédie de l'Islam, 2. ${ }^{\text {a }}$ ed., I, p. 1055, artículo «Bali»). Hay que precisar que el pozo de noria se llama en España “aceña” (ver M. E. Montaner Salas, Norias, Murcia, 1982, p. 97) o “ceña” (ver E. Diz Ardit - A. García Menargues - M. Gea Calatayud, Norias, Alicante, 1984; E. Barajas, «Contribución al conocimiento del arabismo (an)naura», Revista de estudios extremeños, XLIV, n. ${ }^{\circ} 1$, 1988, pp. 49-66). En Egipto, se le designa con el nombre de “saquia” (ver L. MenAssa - P. LAfERrière, La Sequia, El Cairo, p. 64). Véase también nuestro artículo, en An-na 'ūra en Tunisie aux XVIII et XIX siècles, Túnez, 1988, pp. 200-219). En el plano arquitectural, el pozo de Testour se parece a los de España (ver BAzZANA - BERTRAND - CRESSIER - GUICHARD - MontMEssin, «L'hydraulique agraire dans l’Espagne médiévale», en L'eau et les hommes en Méditerranée, París, 1987, pp. 56 Y 59). Los pozos en Egipto a veces están protegidos por una cúpula (ver G. CASTEL - G. MAHMOUD, "Mausolées des cheikhs», Annales islamologiques de l'Institut Français d'Archéologie Orientale du Caire, El Cairo, XV, 1979, p. 449). Difiere, evidentemente, del pozo romano (ver DespoIs, o. c., p. 121).

Ver A. Hamdane, «Les puits de surface dans la région de Korba», Bulletin de l'Association pour le développement et l'animation rurale, Túnez, n. ${ }^{\circ}$ 16, nov.-dic. 1977, p. 15. Hay que mencionar, a este propósito, que tenemos algunos nombres de poceros (ver A.N.T., registro 49, p. 88, año 1746, registro 111, p. 455, año 1795).

Ver A. Hamdane, o. c., p. 20. 
¿Se trata del principio de los vasos comunicantes, o es simplemente una omisión? La cuestión queda planteada $^{70}$.

Para darun elementoderespuesta, podemos sup onerque estos depósitos estaban construidos con el mismo sistema que las cisternas de las casas, alimentadas por goteras. Esas cisternas servían generalmente para usos domésticos (lavado, colada...) y se alimentaban gracias a las lluvias. A veces, algunas casas o palacios estaban provistas de pozos con noria, para los usos domésticos y también para beber.

En general, cada casa disp onía en su subsuelo de una cisterna (mâŷnl) para recoger las aguas de lluvia. Cada año la cisterna se vacía, se limpia y se enjabelga con cal viva ${ }^{71}$.

Las terrazas de las casas en esos pueblos, como en todo el país, tenían un plano inclinado, lo que permitía que las aguas se dirigieran hacia las canalizaciones que les conducían hacia las cisternas prep aradas en el subsuelo del patio ${ }^{72}$. Además de la cisterna, las casas podían tener también su pozo, en el patio. El patio es, pues, el lugar de humedad por excelencia ${ }^{73}$.

En los pueblos moriscos-andalusíes de Testour, Slouguía, Grish El Wad, Medjez El Bab y Tebourba, las casas tenían tejados con cuatro aguas, cubiertos con tejas huecas, dispuestas de forma muy estudiada, lo que permitía hacer converger el agua hacia los conductos que recogían el máximo de aguas de lluvias ${ }^{74}$. Este sistema, evidentemente, permitía se corrieran rápidamente las aguas, en comparación con el sistema de las terrazas “en forma de espalda de asno”, que son las más corrientes en el país ${ }^{75}$.

Se trata, pues, de una arquitectura funcional, totalmente adaptada al clima y a la mentalidad de la gente del país.

La superficie de esas cisternas es evidentemente proporcional a esos tejados. Su trazado,

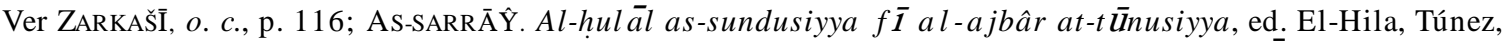

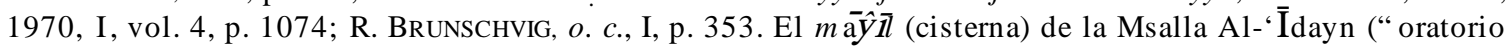
de las dos fiestas”) del barrio de Morkad alimentaba dos fuentes.

Ver P. SeBAg, z«Une relation inédite sur la prise de Tunis», Les Cahiers de Tunisie, Túnez, XVII. 1969, p. 143; J. ReVAult, «Une résidence hafside: la Abdaliyya à La Marsa», Les Cahiers de Tunisie, XIX, 1971, p. 61; G. MARÇAIS, o. c., II, p. 872. El pozo con noria podía servir también para el riego, en Túnez (ver A. DAOULATLI, o. C., p. 153).

Ver F. Mahfoudh, La ville de Sfax..., tesis en la Universidad de París - Sorbona, 1988, p. 195; P. PICARD, Pour comprendre l'art musulman, París, Hachette, 1924, p. 257.

Ver T. Bouchrara-ZANNAD, «Lorsque le corps resiste», Sociétés, Túnez, 28, 1990, p. 23.

Esta arquitectura (techo con 4 vertientes cubiertas con tejas huecas) se encuentra también en construcciones colectivas: mezquitas, záwiyas (oratorios de cofradías o morabitos), hammames (baños calientes), funduques (alhóndigas), fuertes. 
cuadrado o rectangular, se adapta a la forma del patio ${ }^{76}$. Puede tener una profundidad de 5 metros. Esas cisternas pueden tener una pieza que las cubra, en piedra tallada (blat) o en ladrillo relleno, que descansa sobre bóvedas en aristas, generalmente ${ }^{77}$. Se saca el agua destinada a las necesidades domésticas por uno o varios brocales ${ }^{78}$.

Como hemos ya indicado, a propósito de los pozos públicos, estos pueblos moriscos-andalusíes no parecen haberse beneficiado de la política hidráulica de las autoridades tunecinas del período otomano, desde principios del XVII hasta el siglo XX. En efecto, la construcción de depósitos o balsas ("fesquía”, fasqiyya) sólo ha beneficiado a las ciudades como Susa, Kayruán, Sfax, Gafsa y Beja ${ }^{79}$, lugar de paso obligatorio para las expediciones regulares de la Mhalla (mahalla) o ejército fiscal.

\section{ORGANIZACIÓN}

Las pocas indicaciones fragmentarias sobre este aspecto de la cuestión nos permiten constat ar que las fuentes públicas dependían de los suburbios donde estaban instaladas ${ }^{80}$. Así tenemos las de la Medina de Túnez, en Bab Souika (suburbio norte) y de Bab Al-Jazira (suburbio sur $)^{81}$. Se trata, por tanto, de una organización que se basa en una delimitación a la vez territorial y administrativa.

Esto es, al parecer, el resultado de la política seguida por los soberanos en materia de agua. En efecto, la erección de las fuentes públicas así como su cuidado y mantenimiento dependían de las autoridades políticas. No se trata, pues, de un acto de beneficencia, de personas privadas o de cofradías piadosas, como en Oriente.

Ap arentemente, el agua almacenada y distribuida era propiedad de los Habús públicos

La cisterna del fuerte es pañol de la isla de Chikli, en la laguna de Túnez, podía «dar de beber a ocho mil hombres durante cuatro meses», según texto mencionado por P. SEGAB, «Une relation inédite..., p. 141. La cisterna del cuartel Saussier en Túnez (Bab al-Gorjani) podía tener 2.500 m³, según G. Dolot, o. c., p. 297.

Esta clase de construcción es diferente de la de la cisterna de Ramla, en Palestina, dividida en 6 naves por 5 arcadas de 4 arcos cada una, según K.A.C. Kreswell, artículo "Architecture», Encyclopédie de l'Islam, nueva ed., t. I, p. 663 b. En Sfax, el $m \bar{a} \hat{y} \not l$ tiene forma de garrafa, ancha de boca, según F. MAHFOUDH, o. c., p. 195. En Cartago, las cisternas tienen la forma de una bañera redondeada en las dos extremidades, según M. FANTAR, «Le problème de l'eau potable dans le monde phénicien et punique: les citernes», Les Cahiers de Tunisie, Túnez, XXIII, 1975, p. 11.

La záwiya de Sidi Naṣr Al-Garwāšs̄, en el pueblo morisco-andalusí de Testour, comprende una cisterna que tiene un brocal de 45 cms. de diámetro, según A. SAADAOUI, o. c., p. 207.

Ver H. JŪŶA, o. c., pp. 103, 151; MAs‘ŪdI, o. c., p. 120; F. MAHFOUdh, o. c., p. 206 ; S.-M. ZBISS, Monuments..., p.20; P OINSsot, Quelques édifices..., p. 16.

Ver tabla n. ${ }^{\circ} 2$.

Ver A.N.T., dossier 700/4, cartón 62, año 1800; dossier 684, cartón 60, documento 33, año 1874; registro 1773, p. 254, año 1783 . 
(ahbās, awqâf), como es el caso de Estambul ${ }^{82}$. Es la asociación de los awqafes o habices ( $\hat{y} \bar{a}$ ' ‘ ‘ $a$ ) la que se ocup aba de la gestión, del cuidado y de la restauración de esas fuentes ${ }^{83}$, por medio de sus

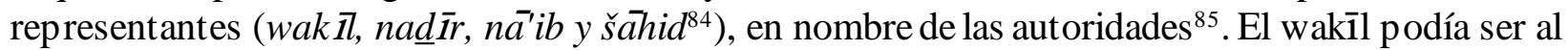
mismo tiempo el šayj, jeque o jefe del suburbio. Es el caso del wakīl de las fuentes del suburbio $\operatorname{sur}^{86}$. Este ejemplo confirma la importancia del wakīl y, en consecuencia, la importancia de las fuentes, para el Estado.

Las rentas de estos awqafes (bienes de manos muertas) destinadas a las fuentes eran imp ortantes. Provenían de tierras (cerealícolas o de huerta) o de alquileres (tiendas, depósitos, mercados) ${ }^{87}$.

Al parecer, era el Estado el que se ocupaba de los "salarios” de los guardianes de las cisternas $^{88}$. Además de los salarios, los guardianes podían recibir ayudas (ihsān) ${ }^{89}$. Hay que mencionar también que se podía conceder salarios a los guardianes de ciertas conducciones de agua (por ejemp lo, en Ghar El Melh) ${ }^{90}$.

¿Había quizás un servicio de mantenimiento de las canalizaciones y de las fuentes, como en

Ver Encyclopédie de l'Islam, $2^{\mathrm{a}}$ ed., artículo «mā'», p. 888.

Ver A.N.T., dossier 684, cartón 60, documento 43, año 1874; dossier 700/4, cartón 62, año 1800.

Ver A.N.T., dossier 386, cartón 32, documento 26, año 1870; dossier 388, cartón 32, documento 32, año 1872; dossier 684, cartón 60, documento 41, año 1874.

Al parecer, cada fuente tenía su wakīl, según documentación del A.N.T., registro 1773, p. 254, año 1783. Hemos constatado también que un wakīl puede ocuparse de varias fuentes (de Rahbat Al-Gnam, de Morkad, de Kallaline) y de la balsa de El Mallassine, según el A.N.T., registro 2303, p. 1, año 1746.

Ver A.N.T., registro 1773, p. 249, año 1781.

Ver A.N.T., dossier 700/4, cartón 62, año 1800 . Las rentas de las fuentes de la Medina y de la balsa de El Mellassine se elevaban a la cifra de 404 riyāles (reales, piastras) en 1756, a 1025 en 1757, a 1505 en 1758 , a 1523 en 1759, a 1528 en 1760, a 1494 en 1761, a 1519 en 1762, a 1547 en 1763, mientras que los gastos se elevan a 425 riyales durante esos mismos años, según el registro 819, p. 29. Las rentas de las fuentes del arrabal meridional de Túnez alcanzan la cifra de 3.689 riyales en 1776, según el registro 1771, p. 74. Estas rentas provienen de 5 tiendas, del depósito de $D \overline{a r} \hat{Y}$ ild (“Casa de las Pieles”, de los Cueros), de varios pozos, de tierras irrigadas y de 3 henchires (tierras cerealícolas), según el registro 1771.

Ver A.N.T., registro 234, p. 5, año 1783. El salario mensual de un sannay o responsable del riego puede alcanzar los 13 riyales, según el registro 232, p. 69, año 1783, y el registro 233, p. 13, año 1783. El wakīl recibía, en cambio, $1 / 4$ de riyāl al día, según el registro 1773, p. 254, año 1783. El bey podía también conceder ayudas (ihssān) de 1 riyāl con ocasión de la Fiesta del Sacrificio (o del Cordero), según el registro 111, p. 138, año 1779. A título indicativo, el precio de una polea puede alcanzar los 2 riyāles, según el registro 233, p. 184, año 1783.

Ver registro 233, p. 24, año 1783.

Ver A.N.T., dossier 386, cartón 32, año 1870. 
Fez $^{91}$ ? ¿Había una reglamentación del aprovisionamiento en agua? ¿Había modalidades de su reparto, como en los oasis del sur tunecino, tal y como lo estableció Ibn Aš-Šabbāt ${ }^{92}$ ? ¿Había un cuerpo de expertos que vigilaban la calidad de las aguas? ¿Había fondos especiales para la limpieza, la reparación de los conductos, la restauración de las fuentes? En definitiva, ¿¿l agua era de pago?

Frente a estas cuestiones, no disponemos más que de dos elementos de respuesta. Una “aportación corporal”(sajära) ${ }^{93}$ seimponíaa los habitantes de Bizerta para construir una conducción de agua (saqāya, sāqiya, “acequia”), cuando los fondos provenían del Estado ${ }^{94}$. Un reclutamiento especial obligatorio fue impuesto a los insurrectos vencidos del Djebel Wislat, a mediados del siglo XVIII, para servir en los trabajos de aducción de agua a Túnez ${ }^{95}$.

También advertimos, en los documentos de archivos, que los wakīles se dirigen a los diferentes responsables o jefes $(a m \overline{i n})$ de las corporaciones: alfareros $^{96}$, herreros ${ }^{97}$, cerrajeros $^{98}$, carpinteros $^{99}$, guarnicioneros ${ }^{100}$, para aprovisionarse en productos necesarios para el buen funcionamiento de las fuentes.

Otro organismo paralelo aparece en la documentación. Se trata de los portadores de agua.

\subsection{Port AdORES de AgUa O AgUAdORES}

El agua de las fuentes públicas se distribuía a la población urbana en odres (guerba, gurba), por portadores de agua (guerbaji $)^{101}$, que transportaban el liquido precioso a los domicilios de los

91 Ver Encyclopédie de l’Islam, 2. ed., artículo «mā̄” .

92 Ver C. ŠAKĪr, «Ibn Aš-Šabbāṭ̣ , Al-Fikr, Túnez, 4, 1982, pp. 76-84.

93 [Nota del traductor] En la Península Ibérica, tanto en época árabe como tras la conquista cristiana, es la “sujra/sofra”. Ver problemática de este sistema, en esta misma revista, M. de EpAlzA - M. J. RuBIERA, «La sofra (sujra) en el Sharq Al-Andalus antes de la conquista catalano-aragonesa», Sharq Al-Andalus. Estudios Arabes, Alicante, 3, 1986, 33-37].

94 Ver dossier 384, cartón 32, documento 110, año 1866, y dossier 385, cartón 32, documento 45, año 1867.

95 Ver IBN ‘ABd AL-'AZĪZ, o. c., pp. 85 y 342.

$96 \quad$ Ver registro 233, p. 188, año 1783.

$97 \quad$ Ver registro 35, p. 34, año 1742.

$98 \quad$ Ver registro 35, p. 111, año 1743.

$99 \quad$ Ver registro 233, p. 184, año 1783.

$100 \quad$ Ver registro 233, p. 172, año 1783.

101 Saqq $\bar{a}$, en árabe clásico (nombre de oficio, “el que distribuye el agua”, como una acequia), garbag $\overline{1}$ en dialectal tunecino (con la terminación turca de nombre de oficio, “el que distribuye el agua en odres”). En Hama (Siria),

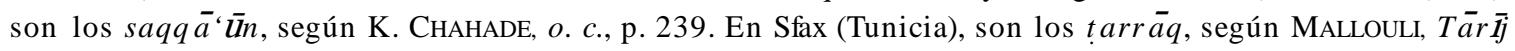
as-siqāaya, Sfax, Louze, 1978, p. 106. 
particulares ${ }^{102}$. A veces, estos porteadores de agua proporcionaban agua potable a los transeúntes sedientos, en vasitos de cobre o de alfarería (hallab). «Estos porteadores recorren las calles en todos los sentidos con caballos cargados de odres llenos de agua, que ceden a los que la necesitan, mediante una pequeña retribución» ${ }^{103}$.

Hay que advertir que actualmentealgunos particulares y también edificios públicos religiosos (escuelas medersa, záwiyas de cofradías, mezquitas, escuelas primarias o kuttāb) ponen a disposición de los transeúntes y de los vecinos una jarra y un recipiente (hallab) para quitarse la sed. ¿Se trata acaso de una pervivencia de esa práctica ancestral?

Algunas indicaciones sacadas de archivos nos informan, por otra parte, que la mhalla (mahalla) estaba acompañada en sus desplazamientos por un cuerpo de porteadores de agua (saqqāya o "sakkaya") ${ }^{104}$. El agua se transportaba probablemente en jarras montadas sobre carros $(\text { karr } \bar{t} a)^{105}$. Los fuertes, así como los fortines, disponían también de saqqāya ${ }^{106}$. Los guardas del palacio del gobierno, en El Bardo, cerca de Túnez, se quitaban la sed con agua de jarras que estaban a su disposición ${ }^{107}$. Si los porteadores de agua en la ciudad eran hombres, el acarreo del agua «era esencialmente femenino en el campo» ${ }^{108}$.

\section{LA EVACUACIÓN DE LAS AGUAS}

En general, el desagüe, tanto de las aguas pluviales como de las aguas usadas, se operaba naturalmente. En efecto, en el pueblo morisco-andalusí de Al-Alia, la calle principal presenta una pendiente hacia Bāb Banzart (“la puerta de Bizerta”). Las calles secundarias, perpendiculares a la vía principal, empujaban las aguas hacia el exterior de la ciudad, como la calle princip al ${ }^{109}$. Ese mismo sistema se encuentra también la pequeña ciudad morisco-andalusí de Zaghouan.

En cambio, en la capital morisco-andalusí de Testour las calles están generalmente provistas

102 En Estambul, estaban organizados en una corporación, según la Encyclopédie de l'Islam, 2. edición, p. 888, artículo «mā'». La misma organización se encuentra también en Madrid, según H. GoBLot, Les qanats, París, 1979, p. 137.

103 Ver C. Monchicourt, Documents historiques sur la Tunisie. I. Relations inédites de Nyssen, Filippi et de Calligaris $(1788,1829,1834)$, París, Société d’éditions géographiques, maritimes et coloniales, 1929, p. 84.

Ver registro 233, p. 131, año 1783, y p.175. También registro 49, p. 85, año 1746.

105 Ver registro 35, p. 111, año 1743.

106 Ver registro 2, p. 120, año 1703.

107 Ver registro 49, p. 20, año 1746.

108 Ver J. DespoIs, La Tunisie orientale..., p. 323.

109 Ver Y. Abdelhady, Réparation urbaine à Al Alya, Túnez, Institut d’Architecture et d’Urbanisme Tunisien, s.a., p.107. 
de canalillos empedrados en medio de las calles ${ }^{110}$.

En los patios de las casas, el desagüe de las aguas se ve facilitado por la disposición arquitectónica. En efecto, esos patios llevan un ligero desnivel destinado a asegurar el desagüe hacia unas mirillas (masküka o nokra, nuqra, "cavidad") ${ }^{111}$.

Por consiguiente, esos pueblos no tienen, como sucede en la ciudad de Túnez, cloacas a cielo abierto (jandak) para evacuar las aguas residuales y otras hacia el lago ${ }^{112}$. Obreros especializados estaban dedicados al servicio de limpieza de esas alcantarillas ${ }^{113}$. Entre las indicaciones recogidas de los archivos, ciertas ayudas eran concedidas a esos obreros por parte de los habitantes del suburbio sur de Túnez, para la limpieza de esas alcantarillas ${ }^{114}$.

Es a la luz de esta presentación sobre la organización de la distribución de las aguas como conviene dar una idea sobre el pap el de los moriscos-andalusíes en este aspecto de sus actividades sociales.

\section{PAPEL DE LOS MORISCOS-ANDALUSÍES}

Algunas indicaciones sacadas de los archivos o de otras fuentes nos permiten medir la importancia del papel jugado por esta comunidad, en la alimentación y en la distribución de las aguas.

Evocando las actividades económico-agrarias, el investigador alemán H. L. Kress afirma que «las canalizaciones del acueducto romano que había caído en ruinas... fueron restauradas por los andalusíes» ${ }^{115}$. Revault, p or su parte, escribe, a propósito del riego en los jardines, que «la irrigación del jardín (sāniya) está asegurada por una o varias norias (na 'üra), cuya instalación en pozos de la capital y de las propiedades de sus alrededores es todavía obra de inmigrantes andalusíes» ${ }^{116}$. Hay que investigar algo más.

Algunos ejemplos podrían iluminarnos más sobre ese papel que asumieron los moriscos y sus descendientes, los andalusíes. Efectivamente, la inscripción del sabīl de Yúsuf Dey en Bizerta precisa que el maestro de obras (mu 'allim) de la fuente fue Dísim el Andalusí117. Hmida An-Nīgrū

110 Ver A. SAADAOUI, o. c., p. 339.

111 Ver J. Revault, Palais et demeures de Tunis, XVIe-XVIIe siècles, París, C.N.R.S., 1980, p. 60.

112 Ver R. Brunschvig, La Berbérie orientale..., I, p. 353; IBN 'ABD Al-AzĪz, o. c., p. 58 . E s e jandaq se utiliza en El Bardo como parte del sistema defensivo (id., p. 327). Estaba unido al de Túnez, según IBN ABī DĪYĀF, o. c., III, 1963, p. 54.

Ver A.N.T., registro 233, p. 105, año 1783.

$114 \quad$ Ver A.N.T., registro 119, p. 128.

115 Ver S. M. ZBiss - A. Gafsi - M. Boughanmi - M. de Epalza, o. c., p. 143.

116 Ver J. Revault, Palais..., p. 73.

117 Ver R. Dhaouadi, Hātihi Binzart, Bizerta, Association de la Sauvegarde de la Médina de Bizerte, 1980, p. 156. 
(En Nigro) fue contramestre (nādir, “inspector”) cuando se construyó la fuente (sabbala) de Bab Saadoun ${ }^{118}$. Muhammad Al-Milyānī Al-Andalusī era experto(jabīr) en las restauraciones defuentes, en Bizerta ${ }^{119}$.

Ar-Ramundo (el origen español de este nombre está muy claro) fue responsable de la contabilidad en el momento de las construcción de la fuente y de la feskía (fasqiyya] de El Mellassine $^{120}$. Muhammad Bin Hsine Al-Andalusí fue wakīl del pozo Atig ${ }^{121}$. Sancho fue maestro de obra en la construcción de carretas destinadas al transporte del agua ${ }^{122}$. Abdel Hmid Al-Ariani (originario de Al-Ariana, pueblo refugio de moriscos-andalusíes) fue maestro pocero ${ }^{123}$.

Por otra parte, los documentos nos indican que la limpieza de las balsas de Griat al-Atach, en el camino de Béjà, se había hecho por obreros especializados originarios de varios pueblos andalusíes, especialmente de Tebourba, de Grish El Ouad (Wâd), de Slouguía, de Testour y de Mejez El Bab ${ }^{124}$. Era el jeque (šayj) de Testour el que se ocupaba de toda esa operación ${ }^{125}$.

¿Bastan estos ejemplos o hace falta más documentación y estudios para probar este pap el de los andalusíes?

\section{CONCLUSIÓN}

A pesar de la imp ortancia que han tenido las fuentes-abrevaderos en la vida de Túnez y de los pueblos moriscos-andalusíes, la alimentación en agua dependía, en gran parte, de las precipitaciones. Su suficiencia o insuficiencia tenían que estar ligadas, en parte, a la acción humana. A pesar de los inconvenientes de este sistema, sobre todo desde el punto de vista higiénico, no se podía rechazarlo totalmente, sino adaptarlo, procurando mejorarlo. Tampoco la Tunicia actual ha resuelto totalmente este problema, a pesar de la utilización de una tecnología mucho más puntera que la de las fuentes-abrevaderos.

Por su arquitectura, proporcionada y elegante, las fuentes son pequeñas maravillas arquitectónicas. Ocupan una posición privilegiada en el tejido urbano y en el espacio público.

Por su arquitectura adaptada al clima y a la mentalidad de los habitantes, las fuentes se

118 Ver A. GAFSI, «Aperçu sur les architectes morisco-andalous en Tunisie», Actes du IV Symposium International d'Études Morisques, Zaghouan, 1990, p. 136.

Ver A. GAfsı, «Al-andalusiyyūn fí Binzart», Bizerta, Association de la Sauvegarde de la Médina de Bizerte, 1989, p. 18.

Ver A.N.T., dossier 388, cartón 32, documento 21, año 1864.

121 Ver A.N.T., registro 1771, p. 179, año 1772.

122 Ver A.N.T., registro 35, p. 111, año 1743.

123 Ver A.N.T., registro 2303, p. 55, año 1746.

124 Ver A.N.T., registro 111, p. 287, año 1780.

125 Ver A.N.T., registro 1773, p. 278, año 1780. 
integran perfectamente en el tejido urbano tradicional. La organización pública unida a las fuentes (asociación de los habices) actúa constantemente con una "organización” privada (los porteadores de agua o aguadores), y las dos funcionan maravillosamente para alimentar tanto a la ciudad como a sus habitantes. La comunidad morisco-andalusí jugó un papel importante en este terreno, tanto en el campo de esta organización como en el de la alimentación y distribución del agua.

Traducción de Míkel de Epalza

\section{RESUMEN}

Este estudio recoge información arqueológica, archivística y cronística de toda clase para documentar los sistemas urbanos de obtención, acarreo, conservación y distribución de agua, tanto en Túnez capital como en los pueblos y ciudades pequeñas donde también se instalaron los moriscos y sus descendientes, los llamados andalusíes en su nueva patria, después de su expulsión de España, a principios del siglo XVII. La comparación y, muchas veces, el contraste, entre la capital y sus zonas peri-urbanas campesinas muestran diversas formas de inserción de los descendientes de los musulmanes españoles en el Magreb.

Palabras clave: agua, fuentes, Moriscos, Tunicia.

\section{ABSTRACT}

Public fountains in morisco-andalusian towns in Tunisia in the 17th, 18th and 19th centuries. This study gathers information from archeological sources, archives and chronicles to document the urban sy stems used to obtain, transp ort, p reserve and distribute water, both in the capital, Tunis, and in the villages and small towns where the Moriscos and their desdencents, the 'new contry Andalusians', settled after being exp elled from Spain in the early 17th century. The comparison and contrast between the capital and the rural hinterland show the varying ways that the descendants of Spanish Muslims adapted to life in the Maghreb.

Key words: water, fountains, M oriscos, Tunisia. 


\section{FUENTES-ABREVADEROS EN LOS PUEBLOS MORISCO-ANDALUSÍES}

\begin{tabular}{|c|c|c|c|c|}
\hline Ciudad o pueblo & Nombre & Lugar & Fecha de fundación & Fundador \\
\hline Bizerte & Sbil Handliss & Quartier des andalous & Sin inscripción & ? \\
\hline “” & Bab Khoukha & Rue sidi Ben Aïsa & 1702 & Ibrahim \\
\hline “” & Bab al madina & Rue des armuriers & 1632 & YoussefDey \\
\hline “” & an Natura & Enfrente del puerto viejo & 1632 & “” \\
\hline “” & du vieux port & Entrada de la médina & 1632 & “” \\
\hline “” & an naggarine & Souk des menuisiers & 1709 & Mustafa \\
\hline “” & Sidi Gaagaa & Rue sidi Gaagaa & 1699 & Mustafa \\
\hline “” & Bab Gdid & Rue sidi Atig & Sin fecha & $?$ \\
\hline Soliman & as souk & Cerca de la grande mosquée & $1639 ?$ & ? \\
\hline Grombalia & as souk & Souk & 1622 & YoussefDey \\
\hline Zaghouan & as souk & Souk & Sin inscripción $\left({ }^{1}\right)$ & ? \\
\hline “” & ar rahba & Rahba & “” & “” \\
\hline “” & Sidi Ali Azouz & Cerca de la zaouia & “” & “” \\
\hline “” & $?$ & Rue Hédi Chaker & “” & “” \\
\hline “” & Sidi Ali Azouz & interior de la zaouia & “” & “” \\
\hline Grich el Wad & ar rahba & Plaza & no existe $\left({ }^{2}\right)$ & “” \\
\hline Ghar el Melh & Sahib Tabaa & Place de martyrs & Sin inscripción $\left({ }^{3}\right)$ & “” \\
\hline “” & al Bhaiem & Enfrente burg al Wistani & “” & “” \\
\hline Manouba & Hamouda Bacha & Fuera del pueblo & 1793 & H. Pacha“” \\
\hline Sidi Daoud & Sabbala & ? & $?\left({ }^{4}\right)$ & ? \\
\hline
\end{tabular}

1 “Il y a des fontaines et des citernes” d' après Thenevenot qui visita le village en 1659. cf Sebag, P, l'escale... I.B.L.A., 145, 1980, p. 63

2 Signalée par R. Cagnat, H. SAledin, Voyege en Tunisie, Paris, Hechette, 1834, p. 158.

$3 \quad$ Indication orale

$4 \quad$ Signalée par le document 684, carton 60, doc. 43. Année 1874. 


\begin{tabular}{|c|c|c|c|c|}
\hline Bardo & Kouba al Hamra & ? & $?\left({ }^{5}\right)$ & ? \\
\hline Sidi Bou Saïd & Sbil Chérif & $\begin{array}{l}\text { Cerca de la Zaouia de Si di } \\
\text { Bou Saïd }\end{array}$ & $1734-1756\left({ }^{6}\right)$ & Ali Pacha \\
\hline “” & Sahib Tabaa & ? & 1794 & Sahib Tabaa \\
\hline “” & Bir Khalladi & Cerca de la Zaouia & $1734-1756$ & Ali Pacha \\
\hline “ ” & Taïeb Bey & En el camino de la Marsa & 1895 & Taïeb Bey \\
\hline Bir Chouchane & Sabbala & ? & $?\left({ }^{7}\right)$ & ? \\
\hline Zahrouni & “” & ? & $?\left({ }^{8}\right)$ & ? \\
\hline Radès & Chouchit Radès & ? & $?\left({ }^{9}\right)$ & ? \\
\hline Mnihla & Burg Mnihla & $?$ & $?\left({ }^{10}\right)$ & $?$ \\
\hline Burg al Amri & Burg al Amri & $?$ & $?\left({ }^{11}\right)$ & $?$ \\
\hline Béja & Sbil al Hammam & Souk & ? & YoussefDey \\
\hline “” & Griat al Atach & ? & $?\left({ }^{12}\right)$ & Huga \\
\hline
\end{tabular}

5 Laurent d’ Arvieux en 1666. Cf. Sebag, P., la negociation, I.B.L.A., 48 1981, p. 271, Registro 233, p. 119, année 1783.

6 ZBISS, M.S.; SIDI Bou SAÏD, Tunis, S.T.D., 1963, p. 21. Este autor menciona otras fuentes: Belhouane et Barch Hamba.

$7 \quad$ Registro 2308, p. 57, año 1800.

8 Registro 233, año 1783.

9 Registro 1733, p. 295, año 1771. Se trata probablemente del monumento enfrente del lugar de Gouvernorat de Ben Arous, destruido en parte en 1989.

10 Registro 1733 p. 24, 264, año 1776.

11 Registro 233, p. 65, año 1783.

12 Registro 1733, p. 287, año 1780. 


\section{2- FUENTES- ABREVADEROS DE TUNICIA (VER TAMBIÉN PLANO)}

\begin{tabular}{|c|c|c|}
\hline Nombre & Fecha & Fundador \\
\hline \multicolumn{3}{|l|}{ Puertas } \\
\hline 1- Bab Saadun (sikaya) ${ }^{1}$ & 1434 restaurado en 1803 & Al Munstansir \\
\hline 2- Bab al Khadra (sabbala)² & Antes 1800 & ? \\
\hline 3- Bab Sidi Abdesselem(sabbala) ${ }^{3}$ & 1804 & Sahib at Taaba \\
\hline 4- Ibn Tahir (Sbil, Sabbala) ${ }^{4}$ & ? & ? \\
\hline 5-Bab Aliwa (sabbala) ${ }^{5}$ & 1804 & Sahib at Taaba \\
\hline 6- Bab al Falla (sikaya) ${ }^{6}$ & $1758-1781$ & Ali Pacha II \\
\hline 7- Bab al Bahr (sabbala) ${ }^{7}$ & Antes 1800 & ? \\
\hline 8- Bab al Menara (sbil) ${ }^{8}$ & “” & ? \\
\hline 9- Bab al Gadid (sikaya) ${ }^{9}$ & 1395 & Abu Faris \\
\hline 10- Bab al Gibliyya (sikaya) ${ }^{10}$ & $1435-1488$ & Abu Amr Utman \\
\hline \multicolumn{3}{|l|}{ Souks } \\
\hline 11- Bchamkiyya (sikaya) ${ }^{11}$ & ? & ? \\
\hline
\end{tabular}

1 Daoulatli, A., Tunis, P. 135. Gafsi, A., aperçu sur les architectes..., p. 136

$2 \quad$ Registro 2307, p.1

3 Marçais, G., Manuel, II, p. 888. Poinssot, quelques édifices, p. 13.

4 BrunschVig, R., Berberie, I., p. 353.

5 MarçAis, G., Manuel, II, p. 888. Poinssot, quelques édifices, p. 13.

$6 \quad$ IBN ABi DiAf, op. cit, II, 1977, p. 175.

$7 \quad$ Registro 2307, p.1

$8 \quad$ Idem

9 Daoulatli, A., Tunis, P. 291. Epalza, M., Tuhfa, Roma, Academia Nazionale dei Lincei, 1971, p. 257.

10 As SARRAG, op. cit, p. 1085.

11 IBN ABi DiAf, op. cit, II, 1977, p. 37. 


\begin{tabular}{|c|c|c|}
\hline 12- At Truk (sabbala) ${ }^{12}$ & Antes 1800 & ? \\
\hline 13- Wzar (sabbala) ${ }^{13}$ & XVIII & $?$ \\
\hline 14- Sarragine (sbil, sabbala) ${ }^{14}$ & Antes 1800 & ? \\
\hline 15- Blat (sabbala) ${ }^{15}$ & Antes 1800 & ? \\
\hline 16- Falka (sabbala) ${ }^{16}$ & “” & ? \\
\hline 17-Etoffes (sbil) ${ }^{17}$ & XVII & ? \\
\hline 18- Attarine (sbil) $)^{18}$ & “” & $?$ \\
\hline 19- Fakka (sbil) ${ }^{19}$ & $\mathrm{XV}$ & ? \\
\hline 20- Chaouachina (sebbala) ${ }^{20}$ & Antes 1800 & ? \\
\hline \multicolumn{3}{|l|}{ Medersas } \\
\hline 21- Uthmaniyya (sbil) $)^{21}$ & 1440 & Abu Amr Utman \\
\hline 22- Ibn Trafagine (Sabbala) ${ }^{22}$ & $?$ & $?$ \\
\hline 23-Bachi (sbil) ${ }^{23}$ & $1740-1756$ & Ali Pacha 1er \\
\hline 24- Abu Muhammad (sbil) ${ }^{24}$ & XVII & ? \\
\hline
\end{tabular}

12 Idem. Ibid. Registre 2308, p. 37.

$13 \quad$ Idem

14 Dargouth, S. Les oratoires, Paris, Sorbonne, 1983, note 24.

15 Registro 2307, p.1

$16 \quad$ Idem

17 ZBISs, monuments de Tunis, Tunis, S.T.D., 1971, p. 37. DaOUlatLI, A., Tunis, p. 157

18 Idem. Ibid; Idem. Ibid.

19 Idem. Ibid; Idem. Ibid.

20 Registoe 2307, p.1

21 Al ANSARI, Fahrast, Tunis, Atika, 1967, p. 171. DaoulatLI, A., Tunis, p. 157

22 Bibliothèque Nationale de Tunis (B.N.T.) M.S. nº 09921, p. 37

23 IBn Abi DiAf, Ithaf, 1977, II, p. 175. JULIEN, C.A., op. cit, II, p. 300.

24 ZBISs, monuments de Tunis, p. 37. 


\begin{tabular}{|c|c|c|}
\hline $25-$ Ksar (sabbala) $)^{25}$ & Antes 1768 & ? \\
\hline 26- Gama Gdid (sbil) ${ }^{26}$ & 1767 & ? \\
\hline 27- Musalla al Idayn (sabbala) ${ }^{27}$ & 1391,1434 & Abu Faris \\
\hline 28- Kasbah (Sabbala) ${ }^{28}$ & ? & ? \\
\hline \multicolumn{3}{|l|}{ Plazas } \\
\hline 29- Rahbat al Gnam(sabbala, sikaya) ${ }^{29}$ & Antes 1746 & Husayn Bey 1er \\
\hline 30- Rahbat al murkad (sabbala, sikaya) ${ }^{30}$ & $1758-1781$ & Ali Pacha II \\
\hline 31- Kaadine (sabbala, sikaya) ${ }^{31}$ & $1705-1740$ & Husayn Bey 1er \\
\hline 32- Kallaline (sabbala) ${ }^{32}$ & Antes 1746 & ? \\
\hline 33- Halfaouine (sabbala) $)^{33}$ & Antes 1800 & ? \\
\hline 34- Sidi Mardum(sabbala, sikaya) ${ }^{34}$ & ? & ? \\
\hline 35- Tabbanine (sabbala) ${ }^{35}$ & Antes 1800 & $?$ \\
\hline 36- Ras ed Darb (sabbala) ${ }^{36}$ & Antes 1876 & ? \\
\hline
\end{tabular}

$25 \quad$ Registro 2307 p.1; Registro 1773, p.107.

26 ZBISs, monuments musulmans d’époque husseinite, p. 21.

27 BrunschVIG, R., Berberie, I., p. 353.

28 AS SARRAG, op. cit, p. 1085.

29 ZBISS, monuments de Tunis, p. 21; Registro 2303, p.1

30 ZBISS, monuments de Tunis, p. 21; Registoe 2303, p.1, antes 1746 según este documento.

31 ZBISs, monuments de Tunis, p. 21

$32 \quad$ Registro 2303, p.1

33 Registro 2307, p.1

34 IBN As SAmma, al adilla, Tunis, Dar al Kitab, 1984, p. 111.

35 Registro 2307, p.1

36 Dossier 700/4, carton 62. 


\begin{tabular}{|c|c|c|}
\hline 37- Rahba (sabbala) ${ }^{37}$ & Antes 1874 & ? \\
\hline \multicolumn{3}{|l|}{ Kuttabs } \\
\hline 38- Khiari (sabbala) ${ }^{38}$ & Antes 1800 & ? \\
\hline \multicolumn{3}{|l|}{ Zaouias } \\
\hline 39- Sidi Asila (sabbala) ${ }^{39}$ & Antes 1800 & ? \\
\hline 40- Sidi Bin Ziad (sabbala) ${ }^{40}$ & Antes 1800 & ? \\
\hline 41- Sigoumi (sbil) ${ }^{41}$ & $1435-1488$ & Abu Amr Utman \\
\hline 42- Sidi al Michrif(sbil, sabbala) ${ }^{42}$ & $1758-1781$ & Ali Pacha II \\
\hline \multicolumn{3}{|l|}{ Hospitales } \\
\hline 43- Al maristan (sabbala) ${ }^{43}$ & Antes 1800 & ? \\
\hline \multicolumn{3}{|l|}{ Pozos } \\
\hline 44- Al Naggar (sabbala) ${ }^{44}$ & Antes 1876 & $?$ \\
\hline 45- Al maristan (sabbala) ${ }^{45}$ & “ ” & ? \\
\hline \multicolumn{3}{|l|}{ Zona residencial } \\
\hline 46- Dar al Gild (sabbala) ${ }^{46}$ & Antes 1800 & ? \\
\hline
\end{tabular}

37 Dossier 684, cartón 60, documento 33.

38 Registro 2307, p.1

$39 \quad$ Idem.

$40 \quad$ Idem.

41 IBN As SAMma, op cit, p. 128.

42 ZBISS, monuments de Tunis, p. 20; Registro 2307.p.1

43 Registro 2307, p.1

44 Dossier 700/4, cartón 62.

$45 \quad$ Idem.

46 Registro 2307 p.3, año 1800. 


\begin{tabular}{|l|l|l|}
\hline $47-$ Zankat al Kradha (sabbala) ${ }^{47}$ & “” & \\
\hline 48 - Diwan ${ }^{48}$ & Antes 1666 & ? \\
\hline Fuera de la ciudad & & \\
\hline $49-$ Mellassine (sikaya) ${ }^{49}$ & $1758-1781$ & Ali Pacha II \\
\hline 50 - “ ${ }^{50}$ & “” & “ ” \\
\hline
\end{tabular}

47 Registro 2307, p.47, año 1800.

48 Sebag, P., La négociation I.B.L.A., 147, (1981). P. 87.

49 IBN Aвi DiAf, op. cit, II, 1977, p. 211.

50 Idem. Ibid. 


\section{3- POZOS PÚBLICOS}

\begin{tabular}{|c|c|}
\hline Lugares & Situación \\
\hline \multicolumn{2}{|l|}{ Tunis $^{*}$} \\
\hline Bir al Gabal Al Ahdar ${ }^{1}$ & Sobre la colina de la Rabita ${ }^{\text {F.N }}$ \\
\hline Bir al Ilgiyya ${ }^{2}$ & Sobre la elevación de Feddan (junto Ras At-Tabia) \\
\hline Bir atig ${ }^{3}$ & “” \\
\hline Bir de Bad Sidi Abdesselem ${ }^{4}$ & ? \\
\hline Bir de Bad Kartaganna ${ }^{5}$ & ? \\
\hline 7 puits de gassa ${ }^{6}$ & Dgebel al Ajmar F.N \\
\hline Bir de Sidi Touhami ${ }^{7}$ & ? $^{\mathrm{F} . \mathrm{S}}$ \\
\hline Bir Al Morkad ${ }^{8}$ & ? F.S \\
\hline Bir Msid al Michrif & ? F.S \\
\hline Bir Fald ${ }^{10}$ & Gellaz F.S \\
\hline
\end{tabular}

* Tunis avait sous les Hafsides six puits: Bir Al Akwad, Ad Dubyan, Sidi Souf, Bab Souika et deux autres signalés par Al ABDARI. Cf. DAOULATLI, A., op. cit, pp. 16, 153.

(F.N) Faubourg Nord

(F.S) Faubourg Sud

1 Huga, H., op. cit, pp. 103, 157, 313.

2 A.N.T., Dosier 700/4, cartón 62, año 1800; Registro 2307, p. 1.

3 Ibid Abd Al Aziz, H. op. cit, p. 313.

$4 \quad$ Al Masudi, op. cit, p. 122.

$5 \quad$ Daoulatli, A. op. cit, p. 153.

$6 \quad$ A.N.T., Dosier 700/4, cartón 62, año 1800; Registro 2307, p. 1, año 1800.

$7 \quad$ Idem. Ibid

8 Idem. Ibid. Abdelaziz, H. op. cit, p. 313.

$9 \quad$ Abdelaziz, H. op. cit, p. 313.

$10 \quad$ HugA, H., op. cit, pp. 188. 


\begin{tabular}{|l|l|}
\hline Aïlleurs & \\
\hline Bir Chouchane $^{11}$ & En el camino de Bizerte \\
\hline Bir Chouchit Radis $^{12}$ & En el camino de Sousse \\
\hline Bir At Tarraz & \\
\hline Bir Bouita $^{14}$ & “ ” \\
\hline Bir el Bey $^{15}$ & Entre Bir Bouregba et Bou ficha \\
\hline Bir Khanguet Al Hammamet & \\
\hline
\end{tabular}

11 A.N.T., Registro 2308, p. 57, año 1800.

12 A.N.T., Registro 1773, p. 295, año 1771.

13 A et Kassab, F., Técnicas de control del agua en Túnez y sus alrededores en época pre-colonial, in “Agua y poblamiento”, op. cit, pp. 93-102.

14 ZBISs, S.M., monuments musulmans d’époque husseinite, p. 20.

15 Idem. Ibid.

16 Idem. Ibid, p. 21. 


\section{ILUSTRACIONES}

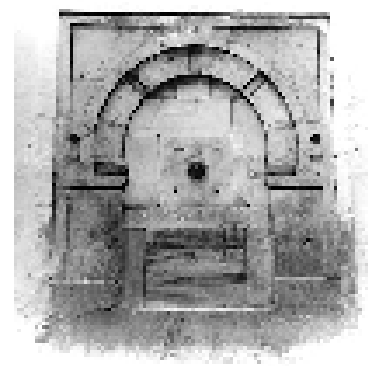

Tunis. Sbil Abi Muhamamad en Halfaouine en 1961

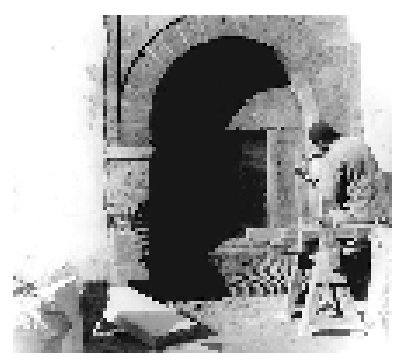

Tunis. Sbil de la Grande Mosquée Zitouna en 1956

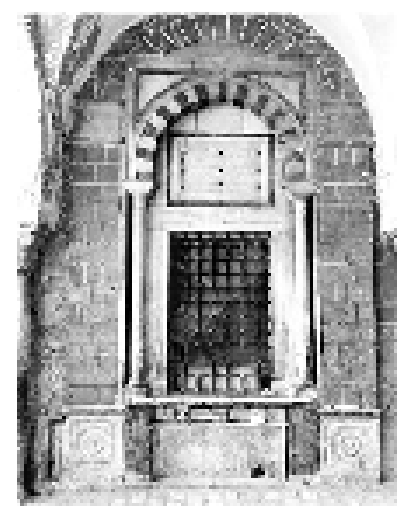

Tunis. Sbil de Jamaa al Jadid en Sabbaghine en 1979 


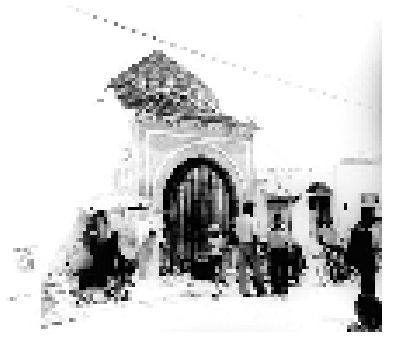

Tunis. Sbil Bab Sidi Abdesselemen 1978

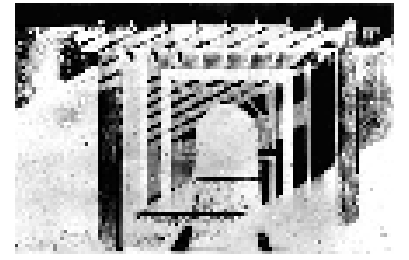

Zaghouan. Sbil en la rue Hédi Chaker en 1990

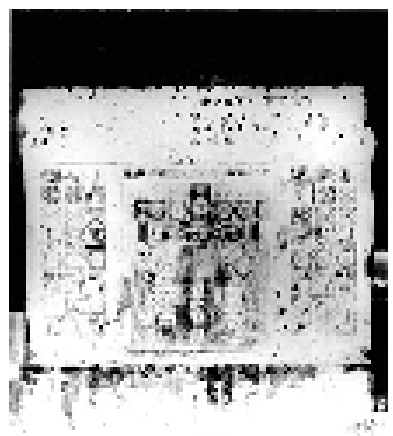

Zaghouan. Sbil Sidi Ali Azzouz en 1990 


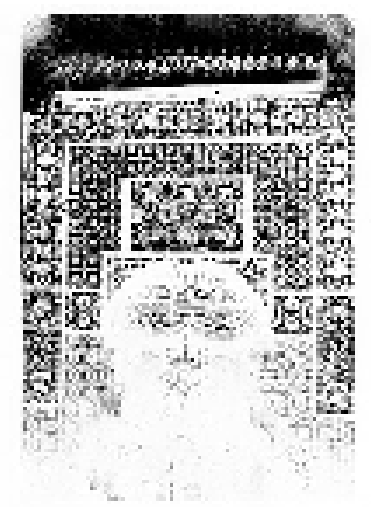

Zaghouan. Sbil ar Rahba en 1990

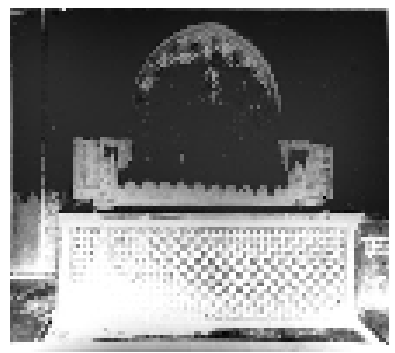

Zaghouan. Sbile en el interior de la zaouia de Sidi Ali Azzouz en 1990

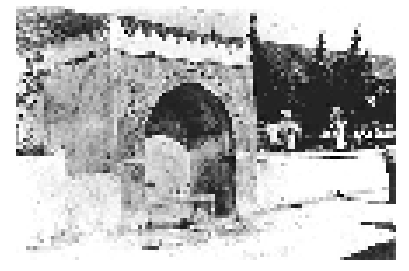

Ghar El Melh (Porto-Farina) Sbil du Burj al wistani en 1975 


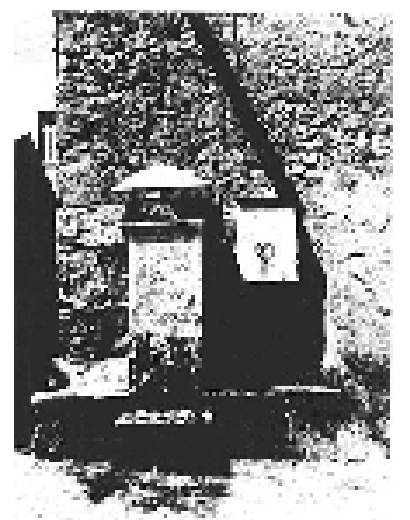

Bizerte. Sbil du vieux Port en 1974

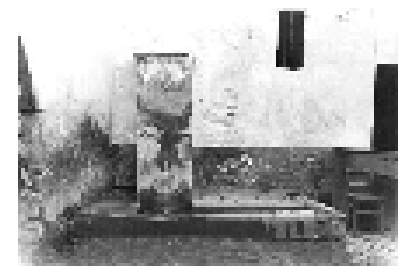

Bizerte. Sbil de la rue an - Najjarine en 1952

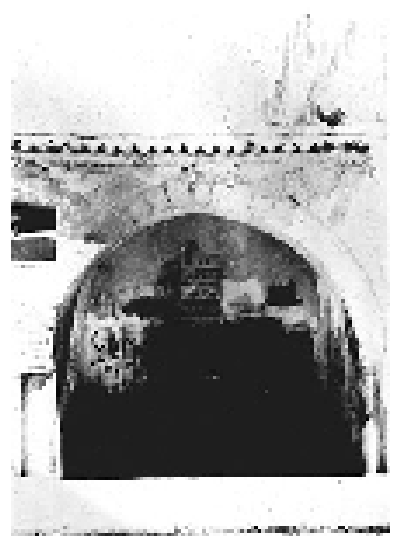

Bizerte. Sbil Bab al Khoukha en 1949 


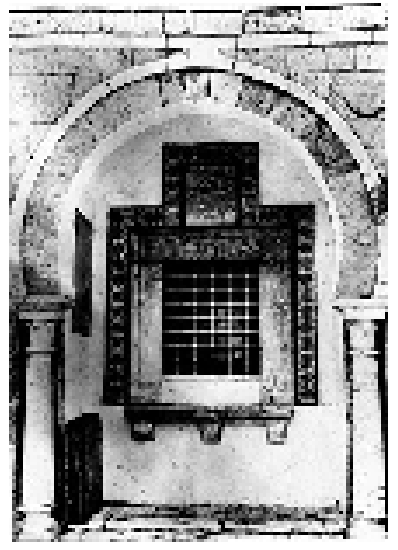

Soliman. Sbil as Souk en 1978

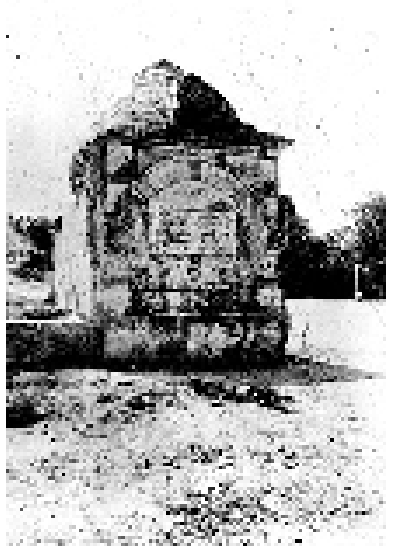

La Manouba. Sbil Hamouda Bâcha en 1962

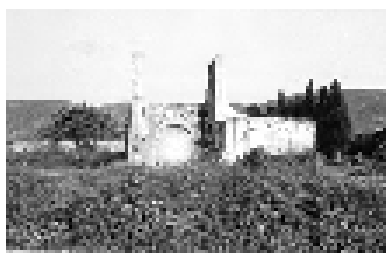

Pozo en Ghar El Melh en 1987 


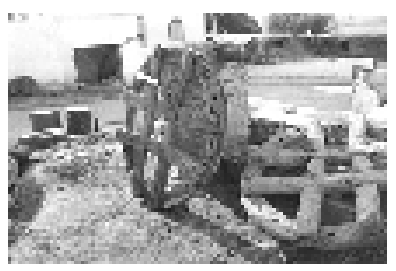

Testour. Restos de la noria de vieux Hamman en 1984

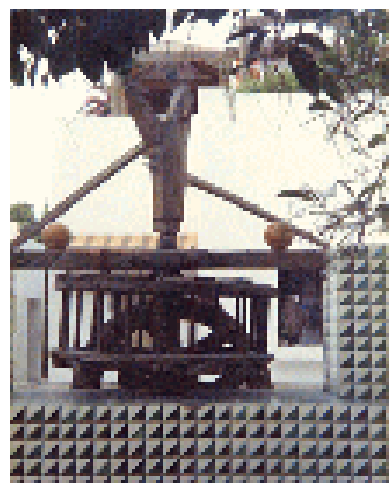

Hammamet. Noria en 1990

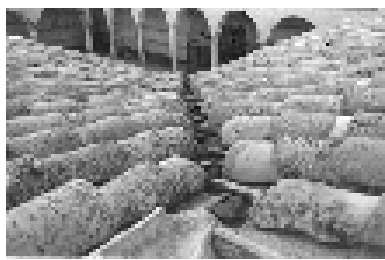

Testour. Sistema de evacuación de aguas pluviales sobre la terraza de la Grande Mosquée en 1984

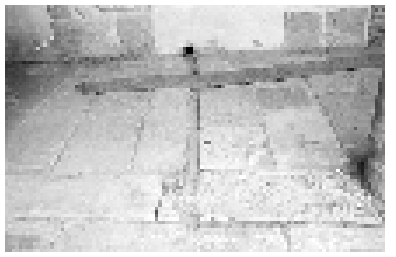

Testour. Sistema de evacuación del agua debajo del pórtico del patio de la Grande Mosquée en 1984 


\section{FOTOS DE LAS FUENTES PÚBLICAS}

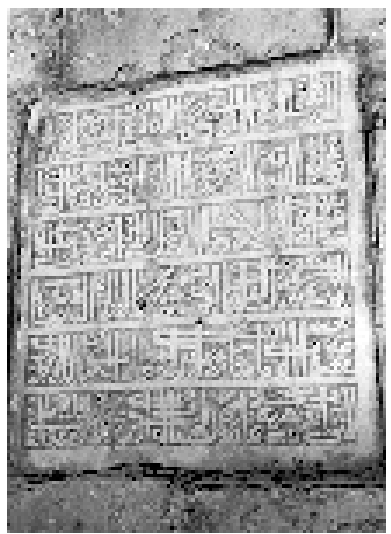

Grombalia: inscripción de la fundación de la fuente

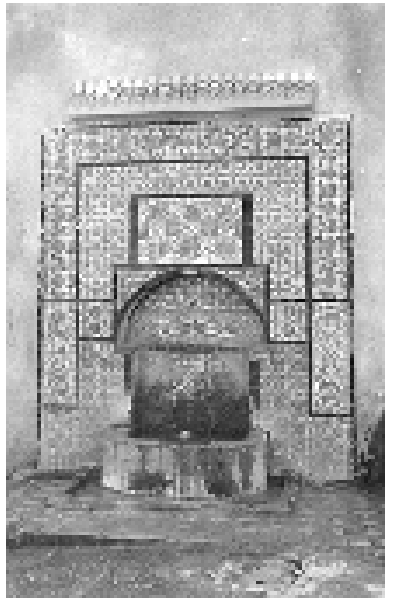

Zaghouan: Fuente de la “ Rahba” 


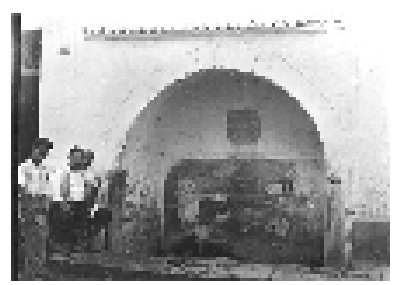

Bizerte: Fuente de Bāb ㅂuhㅡa

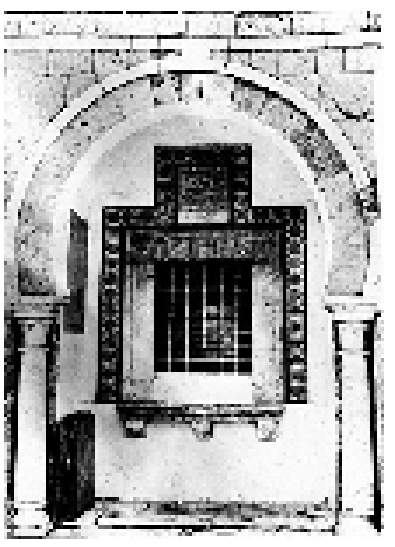

Soliman: Fuente del Soule

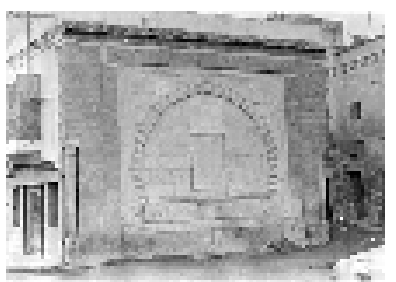

Bizerte: Fuente de YoussefDey 


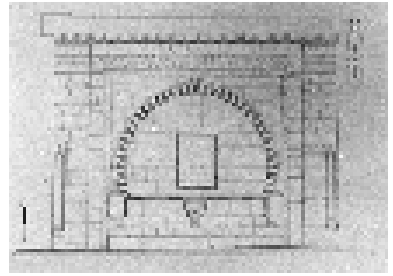

Bizerte: Fuente de Youssef Dey (trazado)

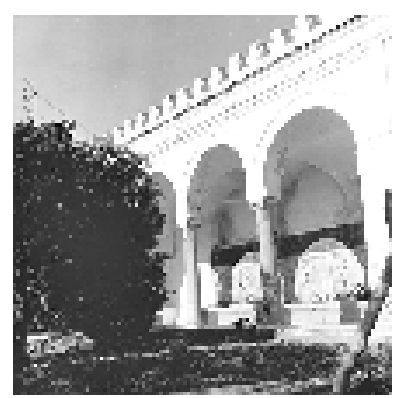

Ghar El Melh: Fuente de "Sahib at-Tabaa”

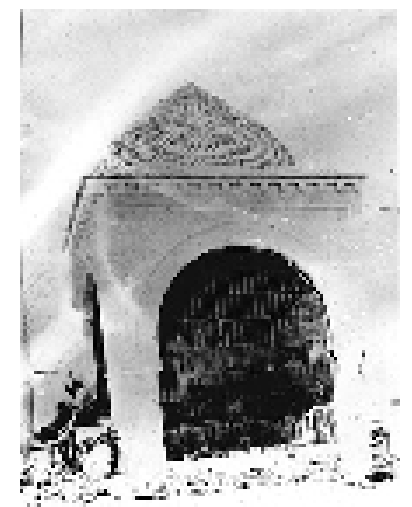

Tunis: Fuente de Bā̄ Sidí Abdesselam 


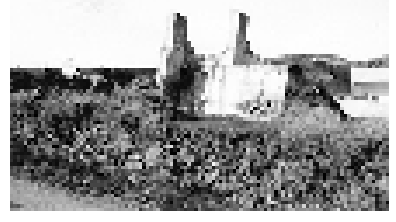

Ghar El Melh: Pozo

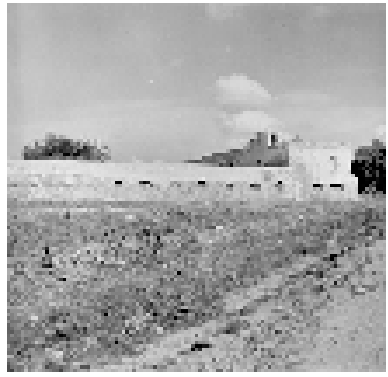

Bir Boure Guba: Pozo 


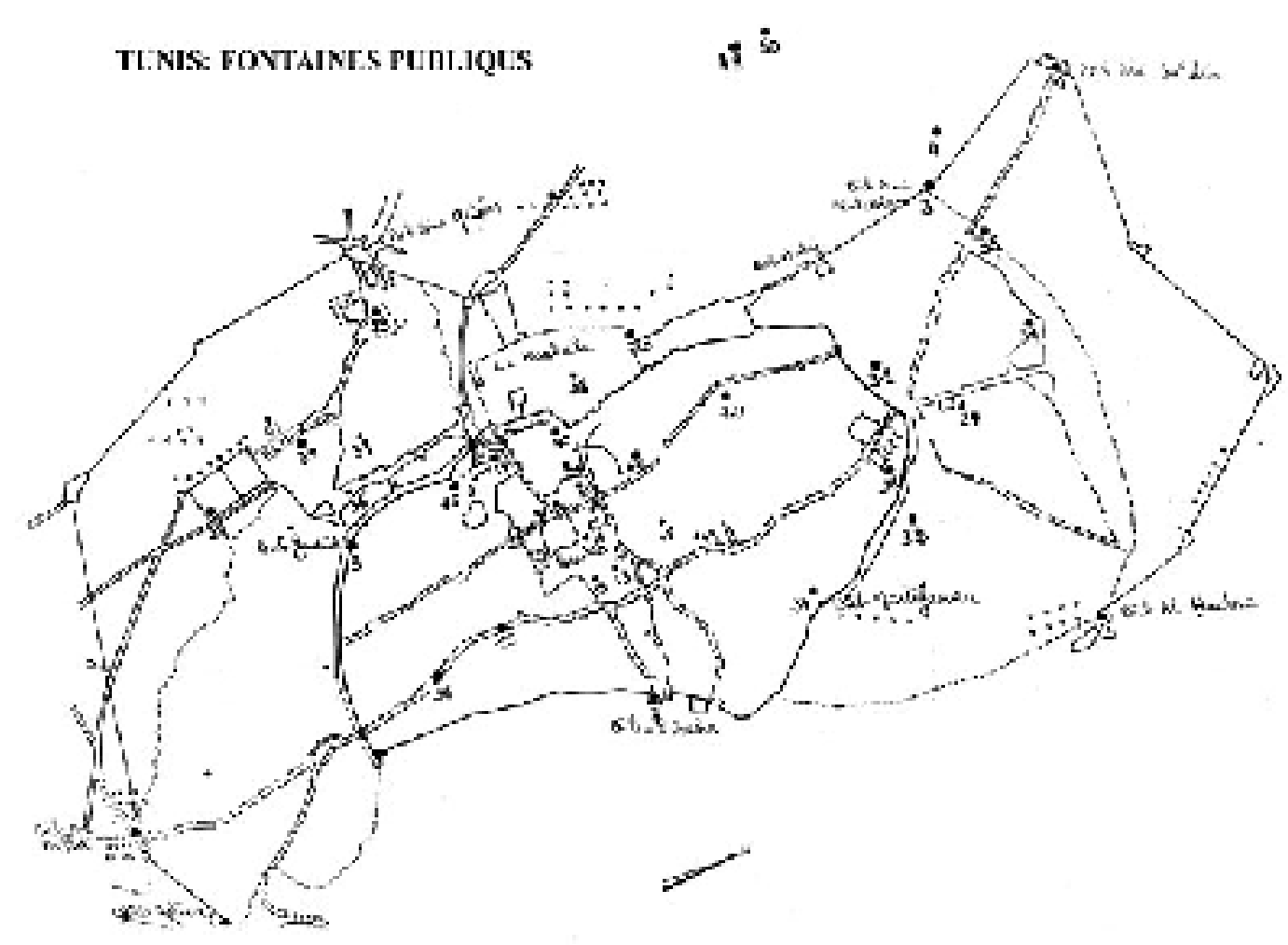




\section{DOCUMENTOS ADJUNTOS}

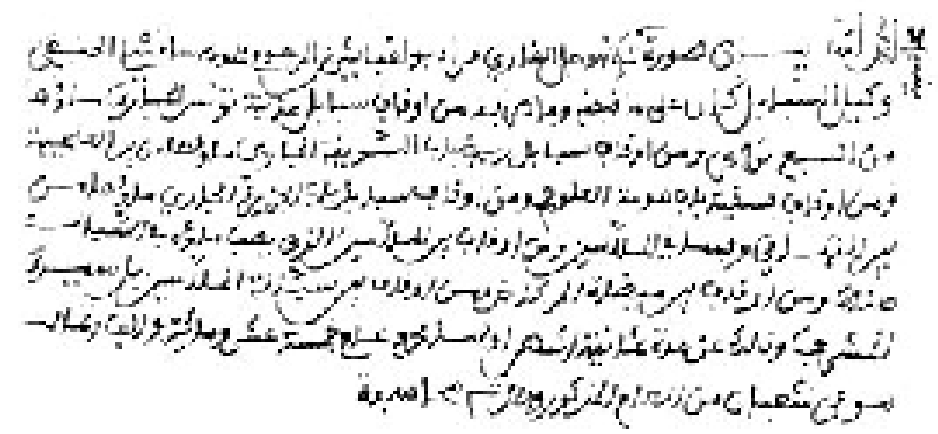

istil

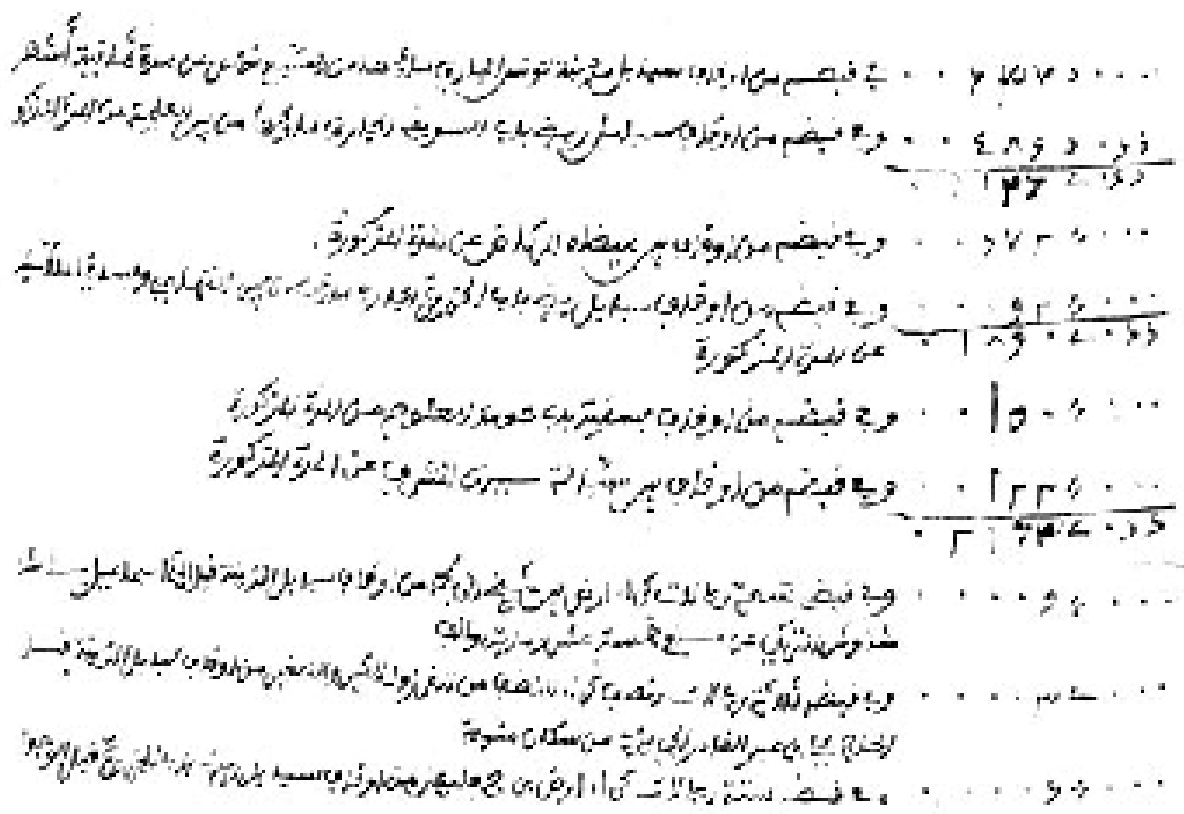

Archives Nationales Tunisiennes (A.N.T.), série historique (S.H), dossier 700/4, carton 62, année 1215/1800. Los habices de las fuentes públicas de Túnez 


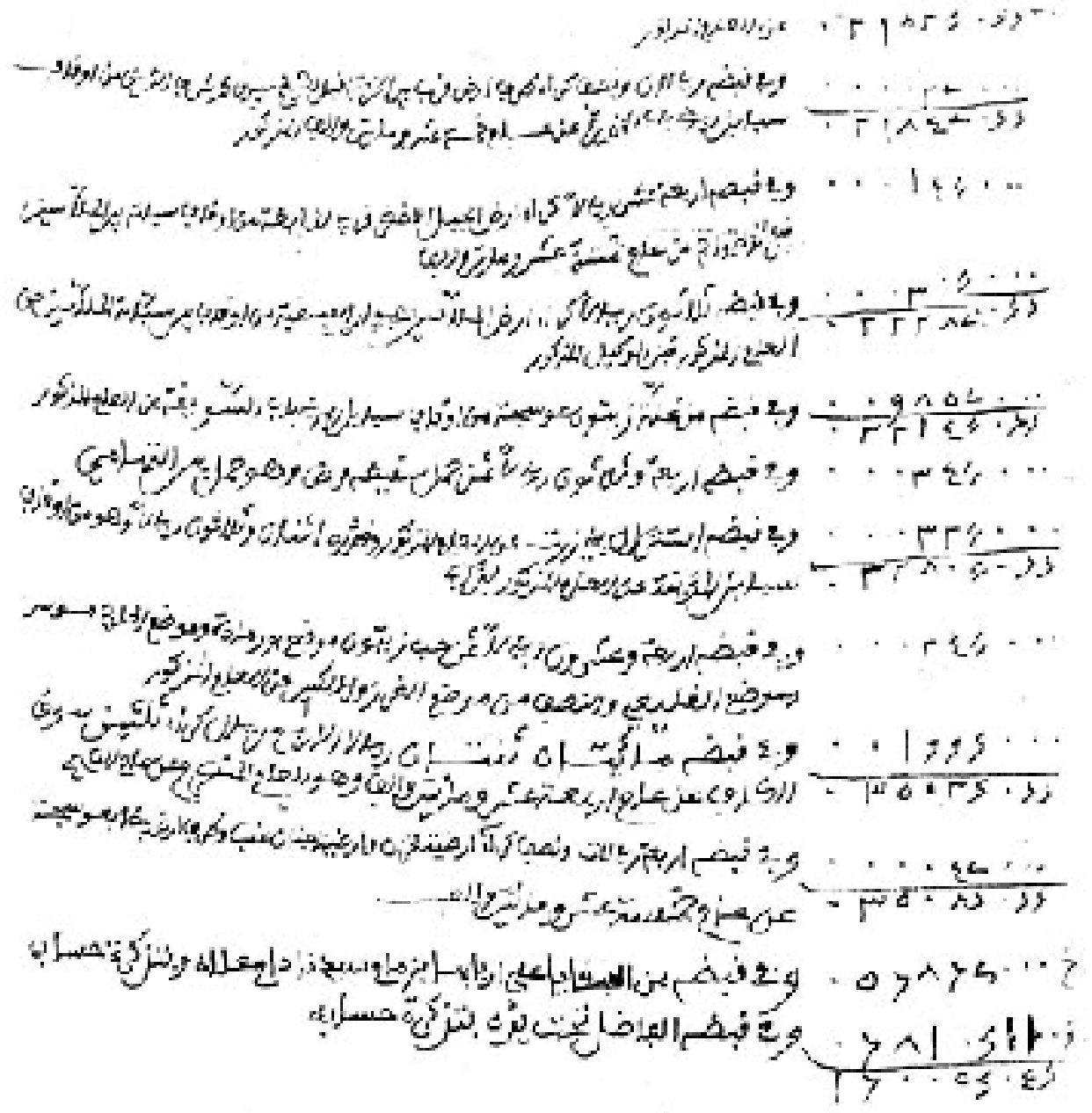

Archives Nationales Tunisiennes (A.N.T.), série historique (S.H), dossier 700/4, carton 62, année 1215/1800. Las habices de las fuentes públicas de Túnez 


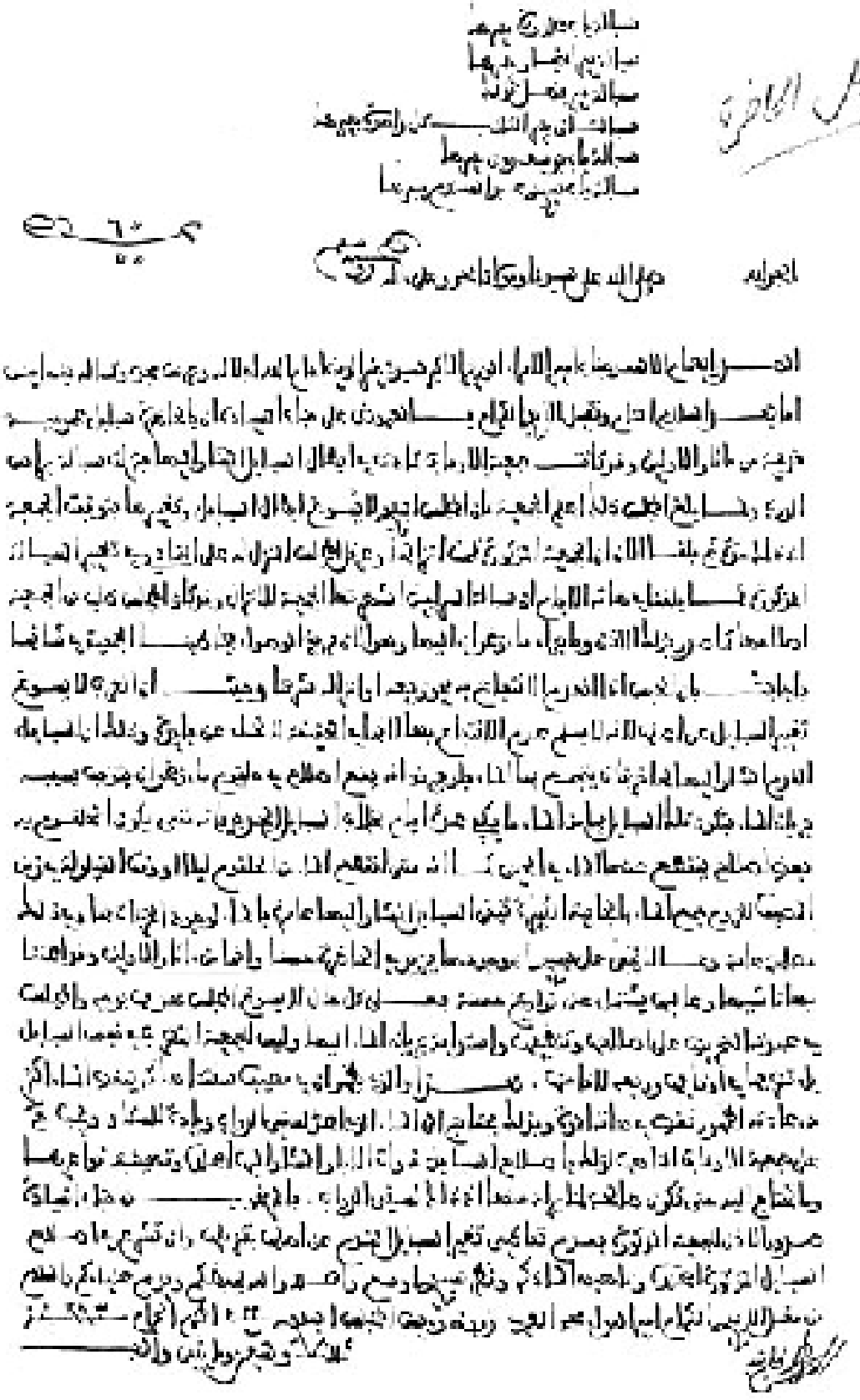




$$
\text { أ }
$$
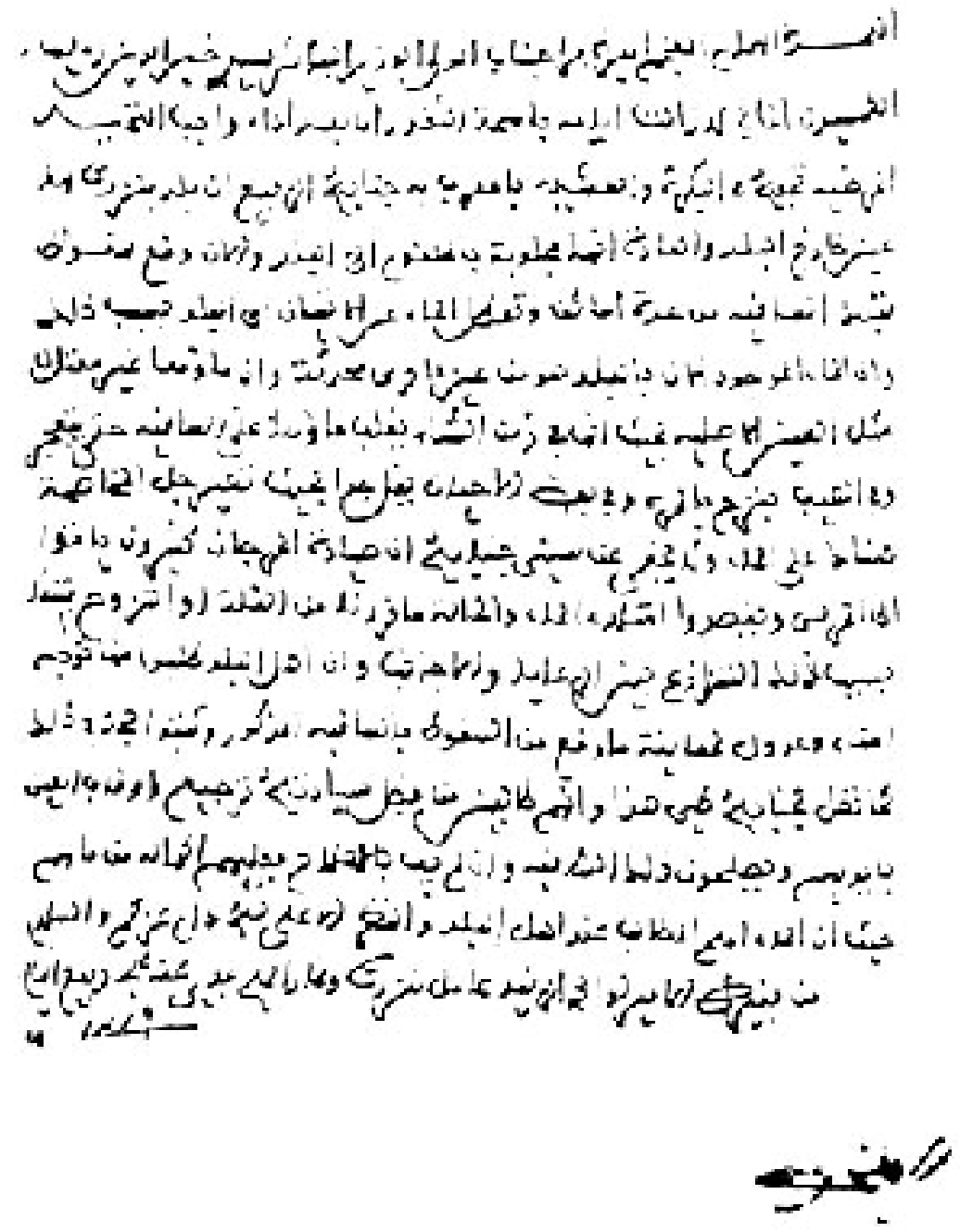

A.N.T., S.H, dossier 388, carton 32, document 19, année 1219/1804. La conducta de agua en Bizerta 


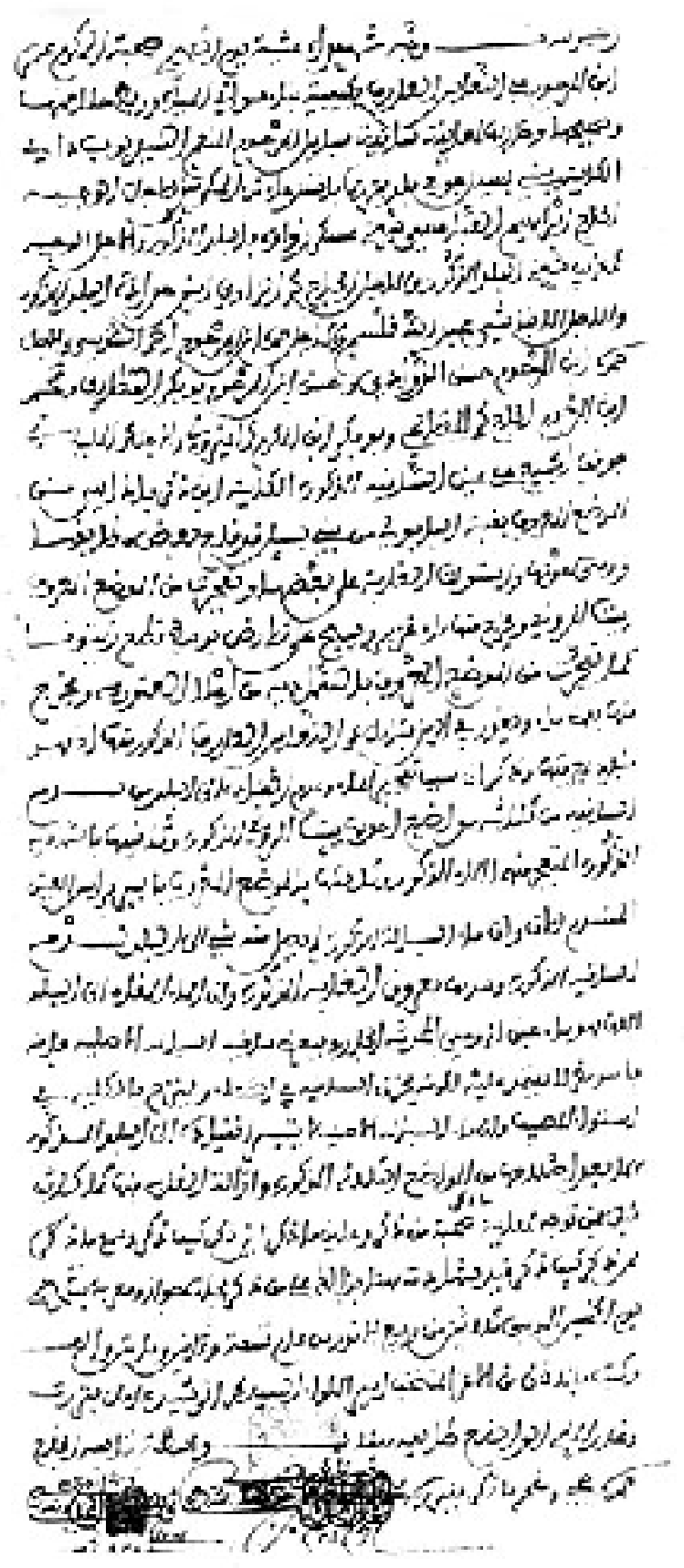

A.N.T., S.H, dossier 388, carton 32, document 21, année 1281/1864. Peritación para la reparación del conducto de agua de Bizerta 


$$
\begin{aligned}
& \text { كتمأن } \\
& \text { ( }
\end{aligned}
$$

-

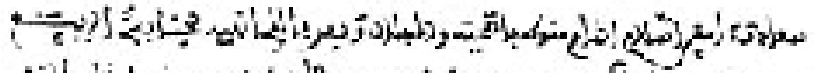

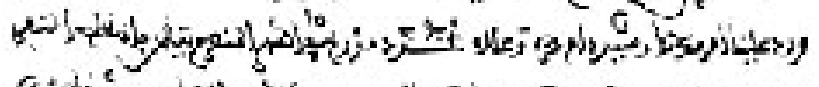

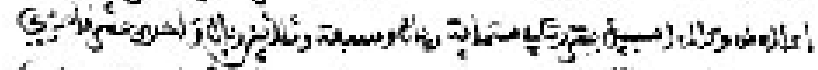

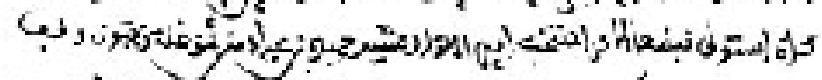
أبغانع الفيه

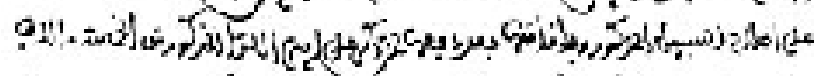

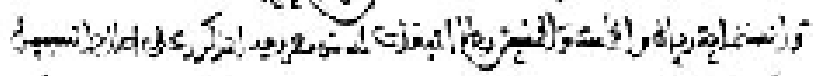

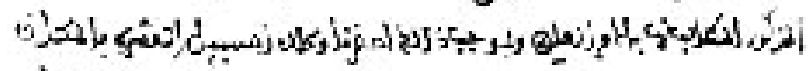

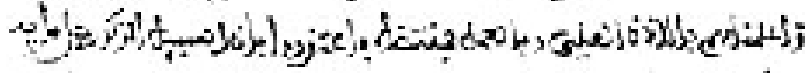

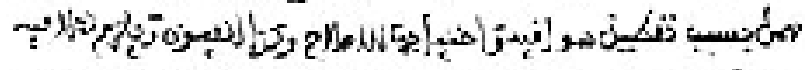

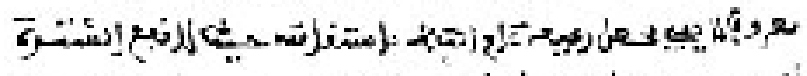

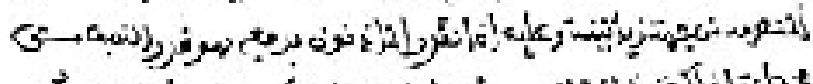

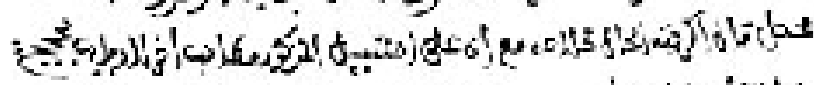
من

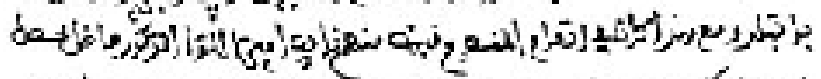

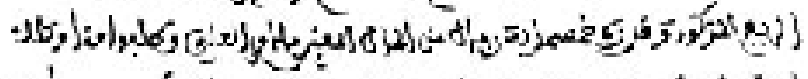

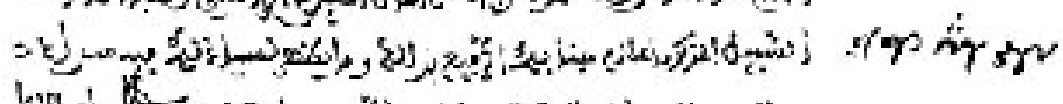
ly)

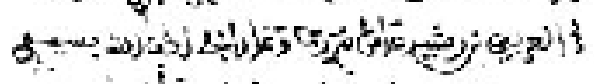

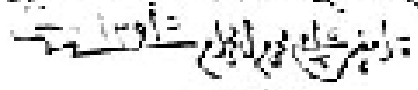

$$
\text { splap }
$$




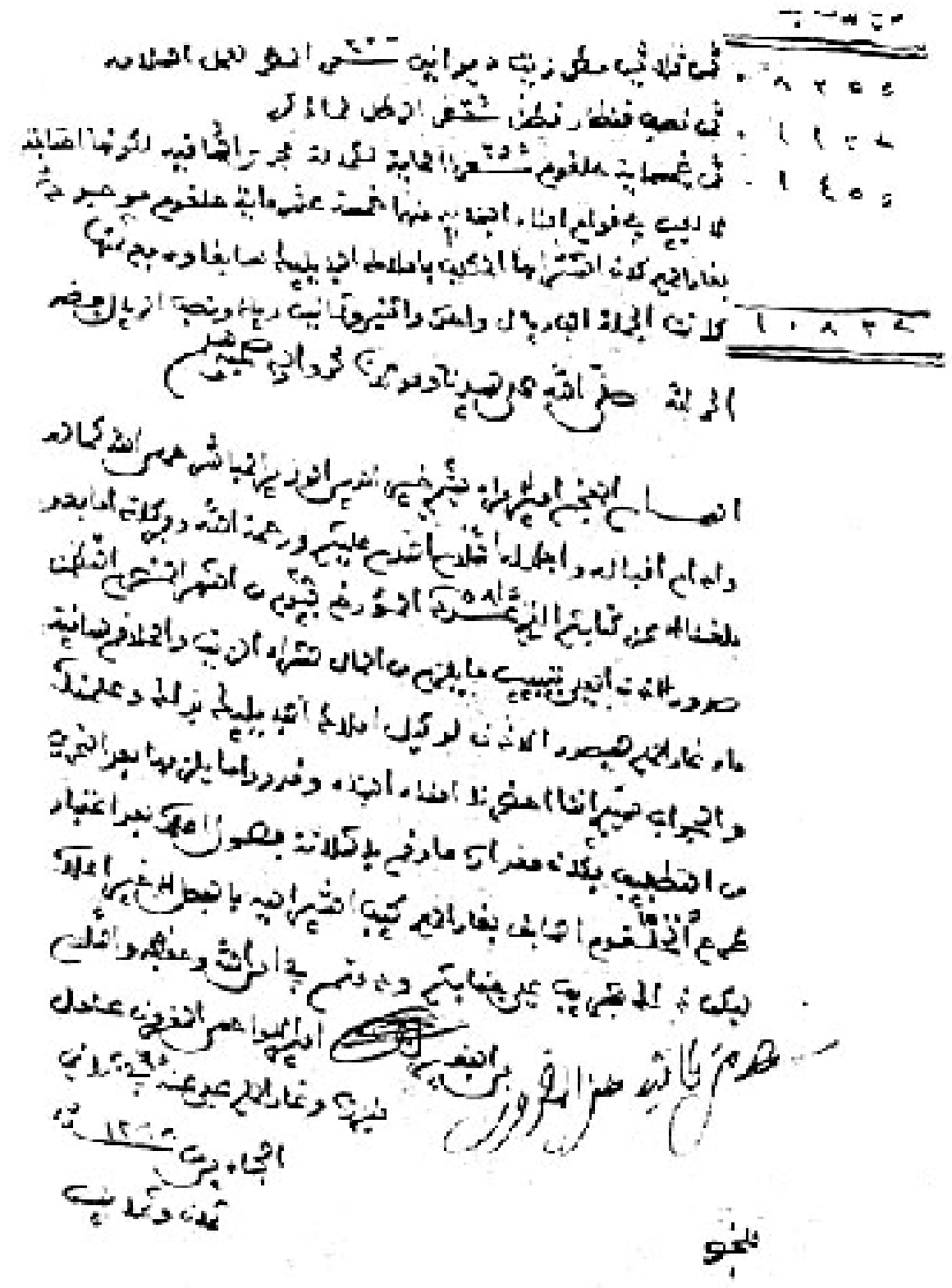

A.N.T., S.H, dossier 387, carton 32, document 45, année 1288/1871. El conducto de agua en Ghar El Melh (Porto-Farina) 